\title{
Article \\ A Nonparametric Approach for Testing Long Memory in Stock Returns' Higher Moments
}

\author{
Massimiliano Giacalone ${ }^{1, *(\mathbb{D})}$ and Demetrio Panarello ${ }^{2} \mathbb{C}$ \\ 1 Department of Economics and Statistics, University of Naples "Federico II", 80126 Naples, Italy \\ 2 Department of Statistical Sciences "Paolo Fortunati", University of Bologna, 40126 Bologna, Italy; \\ demetrio.panarello@unibo.it \\ * Correspondence: massimiliano.giacalone@unina.it
}

Citation: Giacalone, M.; Panarello, D.

A Nonparametric Approach for

Testing Long Memory in Stock

Returns' Higher Moments.

Mathematics 2022, 10, 707. https://

doi.org/10.3390/math10050707

Academic Editor: Stefano Bonnini

Received: 5 February 2022

Accepted: 21 February 2022

Published: 24 February 2022

Publisher's Note: MDPI stays neutral with regard to jurisdictional claims in published maps and institutional affiliations.

Copyright: (C) 2022 by the authors. Licensee MDPI, Basel, Switzerland. This article is an open access article distributed under the terms and conditions of the Creative Commons Attribution (CC BY) license (https:// creativecommons.org/licenses/by/ $4.0 /)$.

\begin{abstract}
In this paper, by considering a model-based approach for conditional moment estimation, a nonparametric test was performed to study the long-memory property of higher moments. We considered the daily returns of the stocks included in the S\&P500 index in the last ten years (for the period running from the 1st of January 2011 to the 1st of January 2021). We found that mean and skewness were characterized by short memory, while variance and shape had long memory. These results have deep implications in terms of asset allocation, option pricing and market efficiency evaluation.
\end{abstract}

Keywords: generalized autoregressive score; skewness and shape; nonparametric test; self-similarity; long-range dependence; financial market

\section{Introduction}

The concept of long memory, also known as long-range dependence or self-similarity of a time series, is related to the persistency of the auto-correlation function. Briefly, it describes whether and how much past events influence the future evolution of the time series.

One of the first studies demonstrating the existence of such phenomenon in real time series data was published by [1]. Later on, Ref. [2] developed the Fractional Brownian motion, a type of stochastic process that incorporates the concept of self-similarity.

In econometrics, Ref. [3] was the first to show that economic time series also share long memory. In financial economics, instead, Ref. [4] presented one of the first studies questioning about the presence of long memory in the stock market. The presence of long memory in stock returns has important implications in finance. For instance, portfolio decisions may become extremely sensitive to the investment horizons [5], the pricing of options under standard assumption is not anymore reliable [6] and the same applies to traditional tests of market efficiency that are no longer valid for time series affected by self-similarity.

Since the outstanding work by [4], hundreds of papers have been focusing on testing the long-memory property of stock returns, developing ad hoc econometric methods for more accurate estimation and forecasting (e.g., [7,8]). Starting from [9], researchers began to investigate whether or not the conditional variance of stock returns is affected by long memory.

Overall, the empirical evidence about long memory in stock markets is mixed. This is especially true concerning returns (i.e., first moment) rather than volatility (i.e., second moment). Indeed, Ref. [4] found positive evidence for most of the stocks included in the NYSE. Similarly, Refs. [10,11] found evidence favorable to short-term dependence. However, in a further study that was published shortly later, Ref. [5] provided empirical evidence against the presence of long memory, gained by means of improved test statistics. Later on, Refs. [12-16] found similar evidence. Nevertheless, favorable evidence was provided by [7], as well as by [17,18], concerning the stock market; by [19], for commodities; 
and by [20], for cryptocurrencies. These examples suggest that there is mixed evidence about the presence of long memory in the first moment, with a strand of literature that claims stock markets to be characterized by long memory and another one that does not. Conversely, on the side of volatility, the academic literature is rich with articles proving the existence of self-similarity; see [8,21-25] for some examples.

Scholars questioned why it is common to find long memory in economic time series. The authors of Ref. [26] investigated whether the observed evidence of long memory is due to nonstationarity in the long period. Nowadays, structural breaks seem to be the most important cause of long memory. In this respect, considering volatility, Ref. [27] discussed the possibility that occasional structural breaks generate long memory in the time series. Similarly, Ref. [28] found that the time series in the sample showing long memory experienced several breaks; moreover, they showed the absence of long memory in the volatility processes after accounting for breaks.

Despite the relevance of higher-order moments in finance is, nowadays, quite well understood (see, e.g., [29-32]), no scholars, to the best of our knowledge, have studied the long-memory property of conditional skewness and shape yet.

Testing long memory in conditional higher moments is relevant in portfolio selection [31-33] and efficient market testing [34]. For example, it is well known that rational investors prefer assets showing high skewness and low shape [35]. If their values change over time, as it usually is [36-39], investors need to closely monitor their over-time fluctuations to be better off.

Through this paper, we aim at testing the existence of long memory in conditional higher moments, by using all the time series of stocks currently quoted in and delisted from the S\&P500 Index. In particular, we consider a nonparametric frequency domain test for long-range dependence [40], focusing on the most relevant higher-order moments in finance, i.e., skewness and shape.

The first step in our analysis consisted in the estimation of the time-varying values of skewness and shape. To this aim, we considered the generalized autoregressive score (GAS) model by [41]. Despite the existence of several statistical methods that can be used for estimating conditional higher moments (e.g., see [38]), the GAS became very popular due to its flexibility (currently, there are more than 250 published papers that use the GAS for modeling conditional moments and/or time-varying distribution parameters (see http:/ / www.gasmodel.com/gaspapers.htm, accessed on 12 February 2022)). Indeed, by using the density score for updating the time variation in the distribution parameters, there is a large set of probability distributions that can be chosen a priori for modeling. Moreover, many well-known processes, such as the GARCH, are special cases of the GAS [41].

Once the variation in higher moments over time is exploited, a statistical procedure for long-memory testing also needs to be defined. In this respect, Ref. [40] recently developed an elegant and simple nonparametric test for long-range dependence by considering the frequency domain representation of the time series. Such test is more robust than alternative tests in terms of size, when the time series are not Gaussian [40]. This is the case of stock returns and market indices, as well as new financial assets such as cryptocurrencies (see, e.g., [42-48]).

The remainder of this paper is structured as follows: Section 2 describes the methodological framework related to both time-varying moment estimation and long-memory testing procedure. Section 3 contains details about the data used in our analysis, consisting of several time series taken from the S\&P500 index. Section 4 provides the main results from the long-memory test. Finally, Section 5 offers some concluding remarks.

\section{Methodology}

\subsection{Conditional Moments Estimation}

In order to estimate the time variation in stock returns' higher moments, we made use of the generalized autoregressive score (GAS) model [41]. The GAS model considers the 
score of the data density function as the main force behind the variation in the distribution parameters' values over time.

Let $y_{t}$ be a time series generated by the following observation density function $p(\cdot)$ :

$$
y_{t} \sim p\left(y_{t} \mid f_{t}, \mathcal{F}_{t} ; \theta_{n}\right)
$$

where $\theta_{n}$ is a vector of static parameters, $\mathcal{F}_{t}$ is the information set at time $t$ and $f_{t}$ is a vector of length $J(j=1, \ldots, J)$ of time-varying parameters depending on the probability distribution specification. The model's information set at a given point in time $t$, denoted as $\mathcal{F}_{t}$, is obtained by the previous realizations of the time series $y_{t}$ and the time-varying parameters $f_{t}$.

In this context, the role of the time-varying parameters' vector $f_{t}$ is crucial, as it contains the measures used to proxy the time variation in the distribution's higher moments.

Let us suppose, for simplicity, that the time series are generated by a Gaussian density $\mathbf{Y} \sim \mathcal{N}\left(\mu_{t}, \sigma_{t}^{2}\right)$. Therefore, each $n$-th time series has the following predictive density:

$$
p\left(y_{t} \mid f_{t}, \mathcal{F}_{t} ; \theta\right)=\frac{1}{\sigma_{t} \sqrt{2 \pi}} e^{-\left(y_{t}-\mu_{t}\right)^{2} / 2 \sigma_{t}^{2}}
$$

where the $J=2$ time-varying parameters are $f_{t}=\left(\mu_{t}, \sigma_{t}^{2}\right)$. The $G A S(1,1)$, for any specification of the density in (1) can be written as

$$
f_{j, t}=\omega_{j}+\mathbf{A}_{j, 1} s_{j, t-1}+\mathbf{B}_{j, 1} f_{j, t-1}
$$

where $\omega_{j}$ is a real vector and $\mathbf{A}_{j, 1}$ and $\mathbf{B}_{j, 1}$ are diagonal matrices. All the scalar parameters $\omega_{j}, \mathbf{A}_{j, 1}$ and $\mathbf{B}_{j, 1}$ are collected in the vector $\theta$. An appealing feature of the GAS model is that the vector of parameters $\theta_{n}$ is estimated by maximum likelihood (for the details, see [41]). Moreover, $s_{j, t}$ is the scaled score of the conditional density (1) at time $t$ with respect to a $j$-th parameter of the time series.

Clearly, the choice of the underlying probability distribution in (1) is very important, since it changes the kind of score considered in (3), thus the considered GAS model. The scaled score $s_{j, t}$ is given by

$$
s_{j, t}=S_{j, t} \cdot \nabla_{j, t}
$$

where $\nabla_{j, t}$ is the conditional $j$-th score at time $t$ for the $n$-th time series, computed as

$$
\nabla_{j, t}=\frac{\partial \log p\left(y_{t} \mid f_{t}, \mathcal{F}_{t} ; \theta_{n}\right)}{\partial f_{t}}
$$

and $S_{j, t}$ is a scaling matrix of appropriate dimension that is usually given by the inverse of the Fisher information matrix, as follows:

$$
S_{j, t}=\left(E\left[\nabla_{j, t} \nabla_{j, t}^{\prime}\right]\right)^{-1}
$$

The aforementioned approach is the standard GAS proposed by [41]. However, the identity matrix can also be considered (e.g., see [49]). Moreover, different GAS models can be used, for instance, by assuming a different scaling matrix $S_{j, t}$.

Considering the Gaussian distribution, the conditional score vector (5) is given by 


$$
\begin{aligned}
& \nabla_{n, 1, t}=\frac{\left(y_{t}-\mu_{t}\right)}{\sigma_{t}^{2}} \\
& \nabla_{n, 2, t}=\frac{\left(y_{t}-\mu_{t}\right)^{2}}{2 \sigma_{t}^{4}}-\frac{T}{2 \sigma_{t}^{2}}
\end{aligned}
$$

with $\nabla_{j, t}=\left(\nabla_{n, 1, t}, \nabla_{n, 2, t}\right)$, where $\nabla_{n, 1, t}$ is the conditional score for the first moment (i.e., the conditional mean) and $\nabla_{n, 2, t}$ is the one for the second moment (i.e., the conditional variance). Therefore, the model's variables and parameters are given by

$$
f_{t}=\left(\begin{array}{l}
\mu_{t} \\
\sigma_{t}^{2}
\end{array}\right), \quad \omega=\left(\begin{array}{l}
\omega_{1} \\
\omega_{2}
\end{array}\right), \quad \mathbf{A}=\left(\begin{array}{cc}
a_{1} & 0 \\
0 & a_{2}
\end{array}\right) \quad \text { and } \quad \mathbf{B}=\left(\begin{array}{cc}
b_{1} & 0 \\
0 & b_{2}
\end{array}\right)
$$

Once the scores are computed, the parameters in (3) are estimated by maximum likelihood. Then, the conditional moments can be obtained by the in-sample predictions $\hat{f}_{j, t}$ as in Cerqueti et al. [39], namely,

$$
\hat{f}_{j, t}=\hat{\omega}_{j}+\hat{\mathbf{A}}_{j, 1} s_{j, t-1}+\hat{\mathbf{B}}_{j, 1} f_{j, t-1}
$$

Nonetheless, assuming a Gaussian distribution in this framework only allows us to study the long memory of the first two distribution moments, while our aim is to study the long-memory property of the first four moments. Therefore, we consider the Skew-t distribution by [50], characterized by the following density:

$$
\begin{gathered}
p\left(y_{t} \mid f_{t}, \mathcal{F}_{t} ; \theta\right)=\frac{2}{\gamma_{t}+\frac{1}{\gamma_{t}}} \frac{\Gamma\left(\frac{v_{t}+1}{2}\right)}{\Gamma\left(\frac{v_{t}}{2}\right)\left(\pi v_{t}\right)^{1 / 2}} \sigma_{t}^{-1} \\
\times\left[1+\frac{\left(y_{t}-\mu_{t}\right)^{2}}{v_{t} \sigma_{t}^{2}}\left\{\frac{1}{\gamma_{t}^{2}} I_{[0, \infty)}\left(y_{t}-\mu_{t}\right)+\gamma_{t}^{2} I_{(-\infty, 0)}\left(y_{t}-\mu_{t}\right)\right\}\right]^{-\left(v_{t}+1\right) / 2}
\end{gathered}
$$

where $\mu_{t}$ is the location, $\sigma_{t}$ the scale, $v_{t}$ the degrees of freedom and $\gamma_{t}$ the skewness. The thickness of the distribution's tails is determined by the parameter $v_{t}$, while $\gamma_{t}$ determines the amount of mass on both sides of location $\mu_{t}$.

Hence, we use the GAS model to obtain estimates of the time series of the parameters in (8). Then, based on such estimates, we test for long memory.

\subsection{Nonparametric Test for Long-Range Dependence}

As previously mentioned, a frequency-domain nonparametric approach [40] is considered for testing short versus long memory.

Let us consider a stationary process $Y_{t}$ with a spectral density of some semi-parametric form as follows:

$$
f(\lambda)=|\lambda|^{-2 d} g(\lambda)
$$

where $0 \leq d<1 / 2$ and $g$ is an even, positive, continuous function on $\lambda \in[-\pi, \pi]$. We can affirm that the process $Y_{t}$ does not show long memory, if $d=0$, such that the spectral density is continuous in $[-\pi, \pi]$. Conversely, we say that the process has long memory if $0<d<1 / 2$, such that the spectral density is unbounded at zero.The authors of Ref. [40] start from the well-known fact that, if $Y_{t}$ are weakly dependent stationary processes, the normalized periodogram is asymptotically exponentially distributed.

$$
\frac{I_{n}\left(\lambda_{j}\right)}{f\left(\lambda_{j}\right)} \stackrel{d}{\longrightarrow} E, \quad \text { as } n \rightarrow \infty
$$


with $\mathrm{I}(\lambda)$ being the periodogram as follows:

$$
\mathrm{I}(\lambda)=\frac{1}{T}\left|\sum_{t=1}^{T} Y_{t} e^{-i \lambda t}\right|^{2}
$$

that is, a consistent estimator for the spectral density of the time series under the absence of long memory. By estimating $f\left(\lambda_{j}\right)$ as the sample average of the periodograms, the test statistics is given by [40]

$$
Q_{n, m}(s)=\sum_{j=1}^{s} \frac{I\left(\lambda_{j}\right)}{\frac{1}{m} \sum_{i=1}^{m} I_{i}\left(\lambda_{j}\right)}
$$

The authors of Ref. [40] showed that the statistics converges in distribution to Gamma with parameters $(s, 1)$, i.e., $Q_{n, m}(s) \rightarrow \Gamma(s, 1)$.

Since the procedure involves sample splitting, $m$ represents the number of sub-samples, each of length $\ell$, and $s$ is the number of frequencies included in the test. Clearly, $m$ and $\ell$ increase along with sample size $T$, such that $m=T / \ell$. According to the authors' suggestion, in what follows, we consider $m=\sqrt{T}$.

Moreover, we note that the choice of $s$, which is crucial for testing, depends on the sample size $T$. Indeed, for short time series, it is possible to build sub-samples characterized by very short length $\ell$, so few frequencies are appropriate for describing whether or not the time series is characterized by long memory. In the case of particularly long time series, Ref. [40] recommends $s \leq 5$ for $T=5000$ and $s \leq 10$ for $T=10,000$.

\section{Data and Descriptive Statistics}

In order to study the long-memory property of the returns' higher moments, we collected data about a large set of stocks. Particularly, we considered the daily time series of the 500 constitutes belonging to the S\&P500 index in the period going from 1 January 2011 to 1 January 2021.

In order to facilitate the presentation of the results, we grouped the stock returns into 11 industrial sectors. The main descriptive statistics by sector are presented in Table 1.

Table 1. Descriptive statistics for group-based stock returns.

\begin{tabular}{cccccc}
\hline Sector & Length & Mean & Variance & Min & Max \\
\hline Industrial & 74 & 0.000650 & 0.004728 & -0.360829 & 0.344278 \\
Health Care & 62 & 0.000652 & 0.004545 & -0.395290 & 0.481849 \\
Information Technology & 75 & 0.000737 & 0.006036 & -0.467855 & 0.420617 \\
Communication Services & 26 & 0.000434 & 0.005322 & -0.455523 & 0.352230 \\
Consumer Discretionary & 63 & 0.000549 & 0.006017 & -0.594142 & 0.365733 \\
Utilities & 28 & 0.000444 & 0.002341 & -0.234522 & 0.257634 \\
Financial & 64 & 0.000442 & 0.003358 & -0.312458 & 0.275358 \\
Materials & 28 & 0.000409 & 0.005236 & -0.321690 & 0.259935 \\
Real Estate & 29 & 0.000379 & 0.002496 & -0.336772 & 0.299941 \\
Consumer Staples & 31 & 0.000466 & 0.003077 & -0.321026 & 0.316513 \\
Energy & 23 & -0.000028 & 0.004668 & -0.773593 & 0.295550 \\
\hline
\end{tabular}

From Table 1, we can observe that the groups have different characteristics. For example, the cluster related to the Energy sector is the one with the lowest (negative) average return and a relatively high variance. The Utilities and Financial sectors are characterized by a very similar mean and a markedly different volatility. Moreover, the Information Technology (IT) sector is the one with the highest number of stocks (75), as well as the highest average return over the considered period.

Clearly, within each group there is also a certain degree of heterogeneity. Indeed, Table 1 shows the average descriptive statistics by group, that is equivalent to considering 
the statistics related to an industry portfolio based on equal weighting. However, industry portfolios are only presented for the sake of exposition simplicity.

To show the degree of heterogeneity in the stock returns' distribution, we show the empirical density of $N=2$ randomly selected stocks for each group (see Figures 1-4).
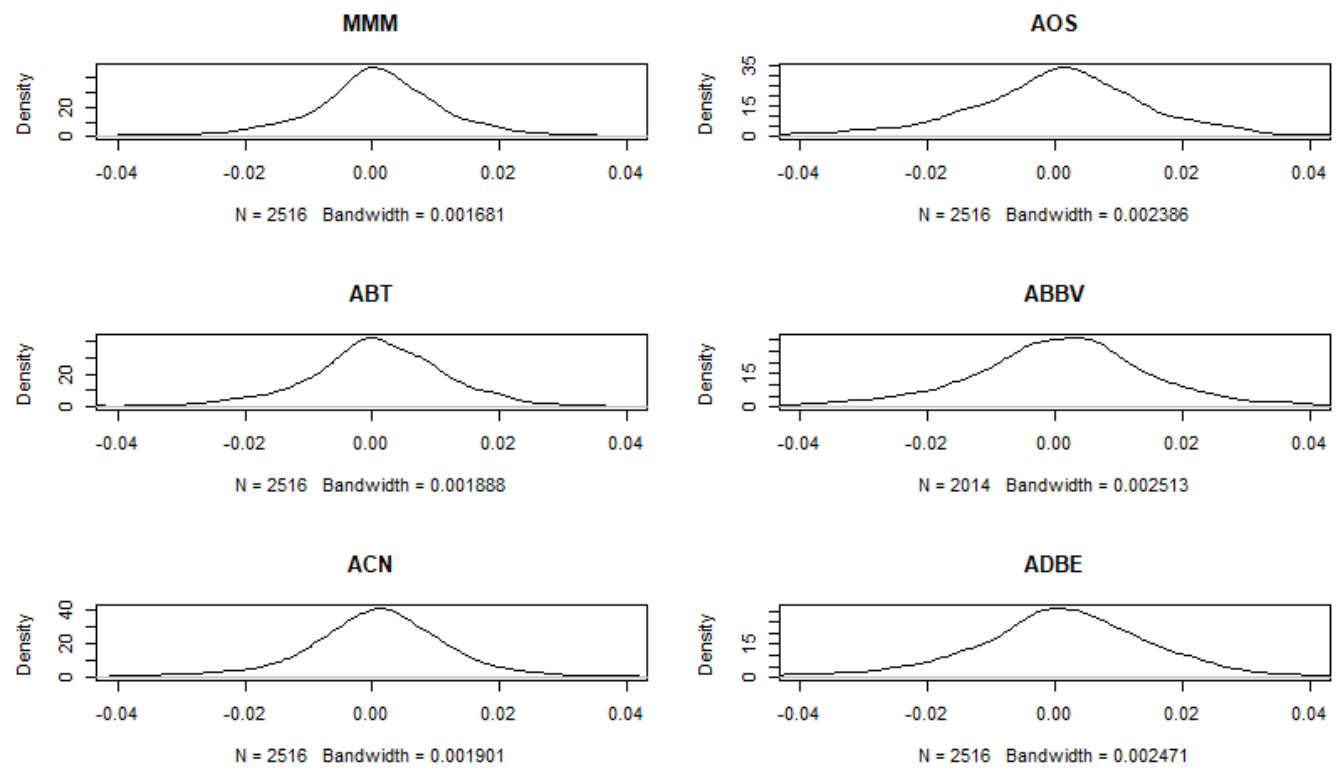

Figure 1. Randomly selected stocks for Industrial, Health Care and IT sectors.
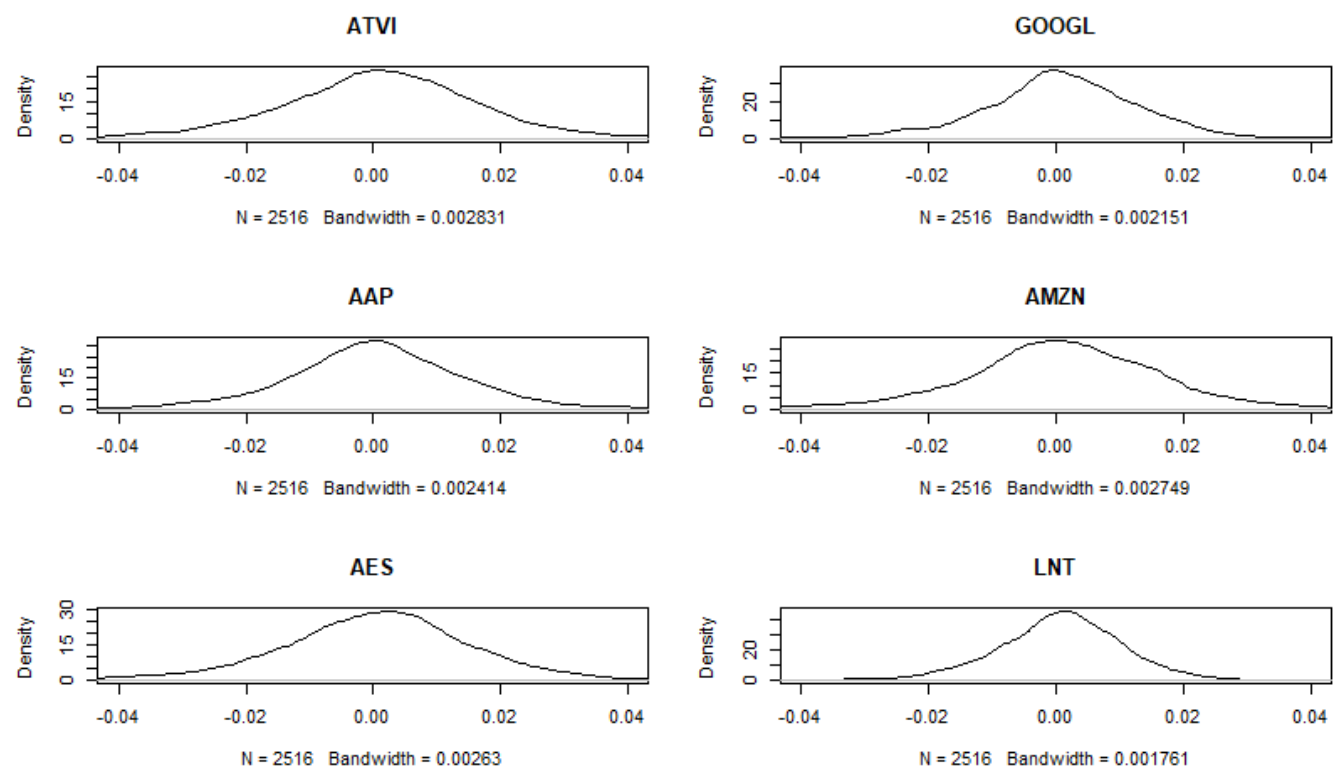

Figure 2. Randomly selected stocks for Communication Services, Consumer Discretionary and Utilities sectors. 
AFL

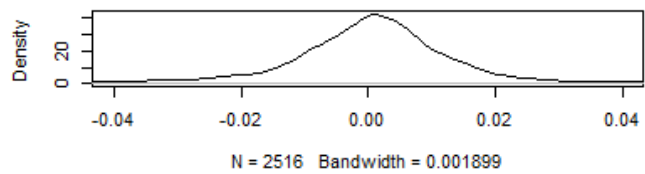

APD

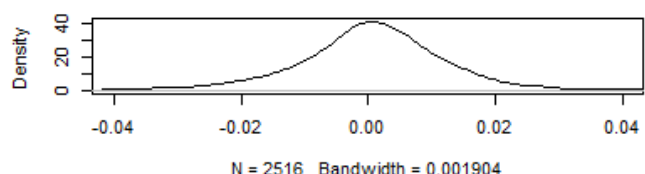

ARE

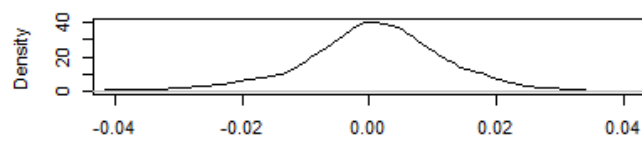

$\mathrm{N}=2516$ Bandwidth $=0.001913$
ALL

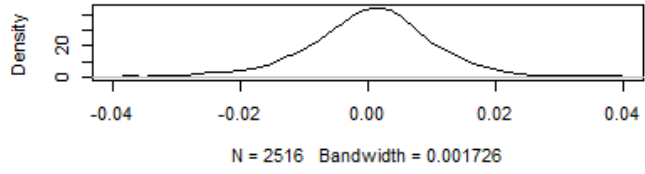

ALB

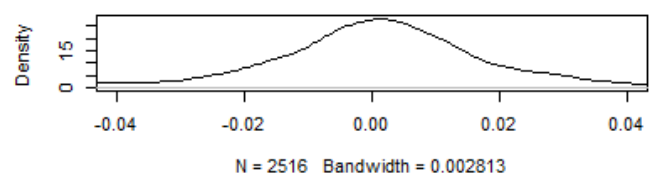

AMT

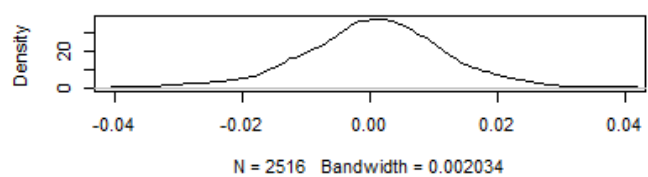

Figure 3. Randomly selected stocks for Financial, Materials and Real Estate sectors.

MO

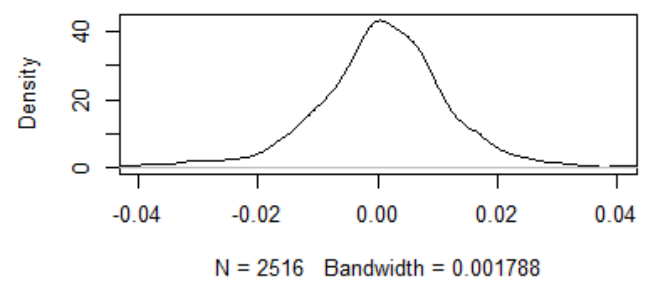

APA

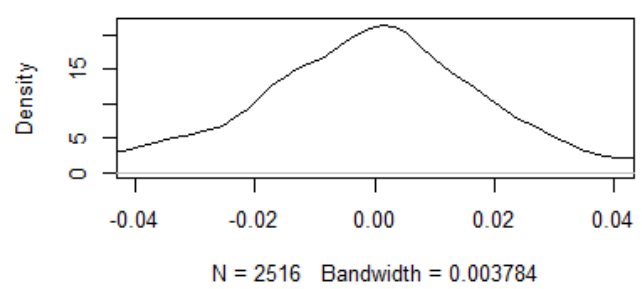

ADM

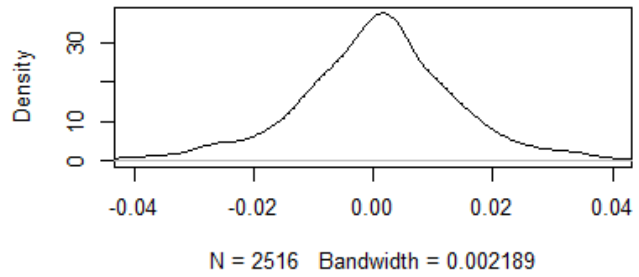

BKR

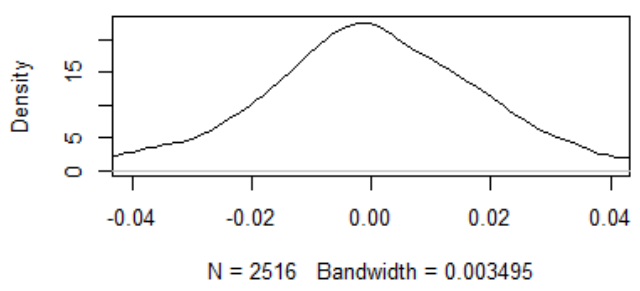

Figure 4. Randomly selected stocks for Consumer Staples and Energy sectors.

It is evident that the empirical distributions are not normally distributed, since they are asymmetric and heavy-tailed. This justifies the opportunity of modeling the stock returns according to a probability distribution that accommodates such features [48,51]. In doing so, it is relevant to investigate whether these higher moments, that are time-varying [37], are characterized by short- or long-memory processes.

Hence, as explained in the previous section, we estimated the conditional moments by means of the GAS model. To provide some examples, Figure 5 shows the estimated time-varying moments for the IBM stock (IT sector), while Figure 6 illustrates those for JPM (Financial sector). 
IBM mean

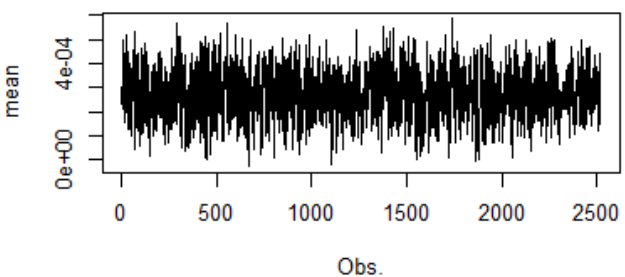

IBM skewness

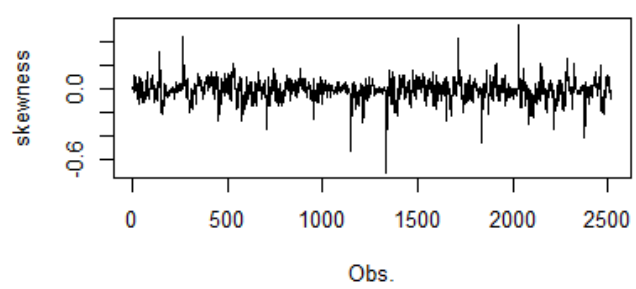

Figure 5. Estimated moments for IBM stock.

JPM mean

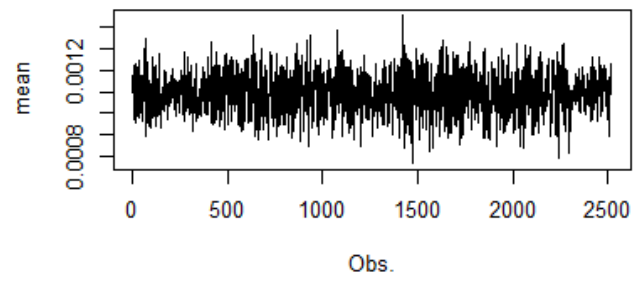

JPM skewness

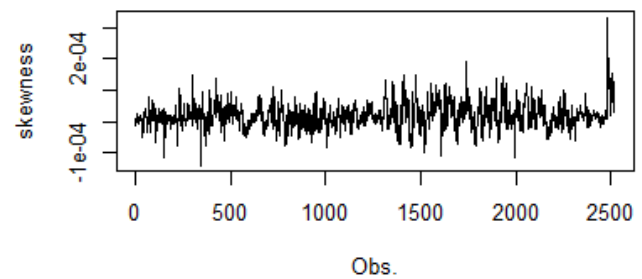

IBM variance

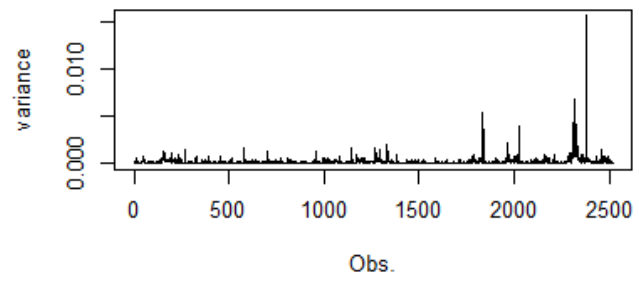

IBM shape

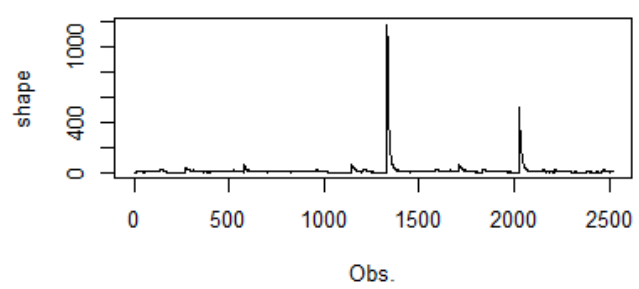

JPM variance

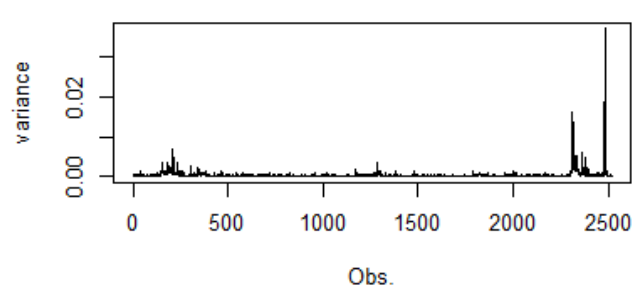

JPM shape

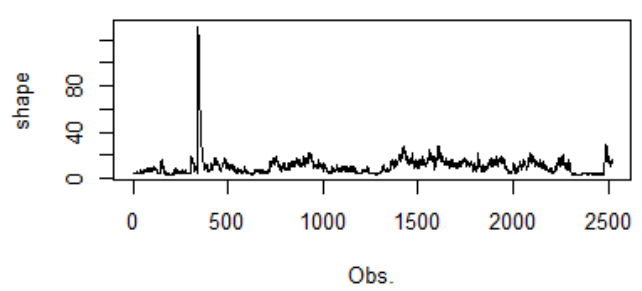

Figure 6. Estimated moments for JPM stock.

It appears clear that, for both stocks, the time-varying skewness evolved over time with a pattern similar to the one of the conditional mean, while shape showed a time variation similar to that of conditional variance. These features hold true for all the stocks in the considered sample; however, we cannot show them all, given the very large sample size.

\section{Main Results}

As previously stated, in order to facilitate the analysis, in what follows, we describe the results of the long-memory test by sector-based groups of stocks. The tables are reported in the Appendix A.

Table A1 shows the nonparametric long-memory results for mean, variance, skewness and shape time series in the case of the Industrial sector.

Table A1 highlights that most of the stocks belonging to the Industrial sector had short memory in the conditional mean, since only $15 \%$ of stocks showed long memory. Therefore, we can argue that the Industrial sector stocks confirmed previous literature findings in terms of absence of long memory. Conversely, in terms of conditional variance, the results 
are different. Indeed, the majority of stocks (61\%) showed long memory in the variance, confirming the findings of a substantial body of research.

The results concerning skewness and shape are the main novelty introduced in the present paper. For the whole set of stocks, skewness showed a time pattern similar to the one of the conditional mean; therefore, we did not expect to find long memory in conditional skewness. By looking at Table A1, we can observe that $51 \%$ of the stocks showed short memory in the skewness. Here, the evidence is mixed and it is not straightforward to obtain a conclusion within this group of stocks. On the side of conditional shape, instead, the evidence is clear, with $97 \%$ of the stocks showing long memory. This happens because the behavior of the shape time series is similar to the one of conditional variance, making it reasonable to assume a sort of "conditional shape clustering" in the returns' time series.

Table A2 shows the results for the Health Care sector stocks. In the analysis of the results, we are interested in confirming those of Table A1. For this group of stocks, as expected, we observed similar results in terms of long memory in higher moments.

More in detail, in terms of the conditional mean, we found that $95 \%$ of stocks were characterized by short memory. Therefore, the evidence suggesting the absence of long memory for the conditional mean is much stronger for these stocks than for those in Table A1. In addition, in terms of conditional variance, the results do not change; the majority $(66 \%)$ of the stocks showed long memory in the variance, again confirming the results of earlier research.

Moving on to skewness, instead, the results are different. Indeed, while Table A1 shows mixed evidence, Table A2 suggests that most of the stocks in the Health Care sector $(60 \%)$ had long memory in conditional skewness. Nevertheless, in terms of conditional shape, only $10 \%$ of the stocks showed short memory, hence confirming the idea that the presence of long memory in shape can be explained by the fact that conditional shape and variance behave in a similar manner.

These results show that, despite an overall picture, there is a certain degree of heterogeneity within the groups.

Table A3 shows the results for the Information Technology stocks. For this group, the conclusions highlighted in Tables A1 and A2 also hold. Indeed, most of the stocks in Table A3 had short memory in the conditional mean (about 83\%) and long memory in the conditional variance $(65 \%)$.

In terms of conditional skewness, there is mixed evidence here as well, with slightly more than half (56\%) of the stocks showing long memory. On the contrary, we confirm that most of the stocks $(91 \%)$ were characterized by long memory in conditional shape.

Table A4 reports the results for the Communication Services stocks. In this case, some results are different than the previous ones.

As regards the conditional mean, most of the stocks (about $85 \%$ ) showed short memory, while $77 \%$ of them were characterized by long memory in variance.

In terms of conditional skewness, we found that $62 \%$ of the stocks had long memory. Hence, Communication Services stocks differed from those belonging to the Industrial, Health Care and IT sectors. In terms of conditional shape, however, the results are similar, with $96 \%$ of the stocks showing long memory.

We present the results for the Consumer Discretionary sector in Table A5. For this cluster, a larger amount of stocks showed long memory in the conditional mean (22\%); nonetheless, as in the aforementioned groups, most stocks appeared to be characterized by short memory. Considering the conditional variance, we found that about $79 \%$ of the stocks were characterized by long memory.

The long-memory nonparametric tests for conditional skewness, instead, provided mixed evidence, since $56 \%$ of the stocks in this group showed long memory. As regards shape, however, we still found that a huge amount of stocks (95\%) had long memory.

Table A6 shows the results concerning the stocks belonging to the Utilities sector. In this case, we have strong evidence suggesting that the considered moments had long memory. Indeed, while only $4 \%$ of the stocks showed long-range dependence for the 
conditional mean, for the majority of stocks, we were led to reject the null hypothesis of short-memory processes for the other conditional moments.

Indeed, according to Table A6, we found that $96 \%$ of the stocks showed long memory in the variance, $68 \%$ in the skewness and $93 \%$ in the shape.

The case of the Financial sector stocks is shown in Table A7. In this group, only $9 \%$ of the stocks had long memory in the conditional mean process, while about $89 \%$ of them showed long memory in conditional variance. Conditional skewness showed, instead, mixed results, with half of the stocks having been characterized by short memory. The outcomes related to conditional shape show that over $92 \%$ of the stocks had long memory.

In light of this evidence, while stock returns were mainly characterized by short (for the mean) and long (for variance and shape) processes, the case of skewness deserved deeper investigation.

The results from Table A8, related to the Materials sector, suggest that skewness did not show long memory for most of the stocks $(68 \%)$ and the same applies to the mean $(86 \%)$. On the other hand, conditional variance and shape showed long memory with a proportion of $71 \%$ and $100 \%$, respectively.

The conditional skewness results shown in Table A8 are very different from those presented in the previous tables; they suggest that, on average, stocks from the Materials sector showed short memory in the skewness process. This fact highlights the heterogeneity across business sectors.

The following table (Table A9) presents the results for the Real Estate sector.

Overall, Real Estate stocks showed short memory in the mean process (only $7 \%$ of them led us to reject the null hypothesis of the presence of long memory). However, as already seen as regards the Utilities sector, the majority of stocks were characterized by long-memory processes for the other higher moments. Indeed, $79 \%$ of the stocks placed in the Real Estate group showed long memory in the variance, $72 \%$ in the skewness and $86 \%$ in the shape.

Hence, for this group, we found that, despite the skewness behaved similarly to the mean process, its time series was, on average, characterized by long memory.

The Consumer Staples stocks are reported in Table A10 below.

Consumer Staples stocks showed, again, short memory in the mean process (87\%). However, higher moments were fully characterized by long-memory processes; most stocks showed long memory in the variance $(68 \%)$, skewness $(61 \%)$ and shape $(97 \%)$.

The last group is based on the Energy sector stocks, the results of which are reported in Table A11.

The Energy sector presented some peculiarities. First of all, it is the business sector with the largest amount of stocks with long memory in the mean (around 35\%). Still, the majority presented short memory in the conditional mean processes.

As regards the other higher moments, the time series proved to be characterized by long-memory properties, with $87 \%$ of the stocks showing long memory in the variance, $74 \%$ in the skewness and $96 \%$ in the shape.

A summary of the results, in terms of both averages and medians, considering all the business sectors taken into account, is provided in Table 2.

Medians were considered in order to account for possible outlier sectors, such as Materials (low proportion) and Real Estate (high proportion) concerning skewness, or the Energy sector concerning the mean. Averages and medians are, however, not particularly distant from one another.

Table 2 confirms the hypothesis that S\&P500 stocks were characterized by a shortmemory conditional mean process overall, while most of the stocks showed long memory in the variance. These two results are in line with the previous literature on the topic.

However, the most interesting results are those provided in the last two columns of Table 2. First, nearly all of the stocks showed long memory in the conditional shape. This can be explained by the fact that the shape patterns were similar to those characterizing 
the variance. Hence, if structural breaks can be seen as the cause of long memory in the variance, this could also hold true for the conditional shape.

Table 2. Long-memory nonparametric tests: summary of the results for all the business sectors.

\begin{tabular}{|c|c|c|c|c|}
\hline & Mean & Variance & Skewness & Shape \\
\hline Industrials & $14.86 \%$ & $60.81 \%$ & $51.35 \%$ & $97.30 \%$ \\
\hline Health Care & $4.84 \%$ & $66.13 \%$ & $59.68 \%$ & $90.32 \%$ \\
\hline Information Technology & $17.33 \%$ & $65.33 \%$ & $56.00 \%$ & $90.67 \%$ \\
\hline Communication Services & $15.38 \%$ & $76.92 \%$ & $61.54 \%$ & $96.15 \%$ \\
\hline Consumer Discretionary & $22.22 \%$ & $79.37 \%$ & $55.56 \%$ & $95.24 \%$ \\
\hline Utilities & $3.57 \%$ & $96.43 \%$ & $67.86 \%$ & $92.86 \%$ \\
\hline Financials & $9.38 \%$ & $89.06 \%$ & $50.00 \%$ & $92.19 \%$ \\
\hline Materials & $14.29 \%$ & $71.43 \%$ & $32.14 \%$ & $100.00 \%$ \\
\hline Real Estate & $6.90 \%$ & $79.31 \%$ & $72.41 \%$ & $86.21 \%$ \\
\hline Consumer Staples & $12.90 \%$ & $67.74 \%$ & $61.29 \%$ & $96.77 \%$ \\
\hline Energy & $34.78 \%$ & $86.96 \%$ & $73.91 \%$ & $95.65 \%$ \\
\hline Average & $14.22 \%$ & $76.31 \%$ & $58.34 \%$ & $93.94 \%$ \\
\hline Median & $14.28 \%$ & $76.92 \%$ & $59.67 \%$ & $95.23 \%$ \\
\hline
\end{tabular}

Second, more than half of the stocks showed long memory in the skewness. This deserves deeper exploration, as this result is weaker than those concerning variance and shape, whose proportions were indeed much higher.

\section{Conclusions}

In this paper, we propose the use of the nonparametric test by [40] to study the longmemory property of stock returns' conditional moments. To this aim, we analyzed the daily returns of the S\&P500 constitutes during the last 10 years (from 1 January 2011 to 1 January 2021).

We estimated the conditional moments by means of the GAS model by [41], a modelbased approach in which the time variation in the distribution parameters is driven by the score of the specified distribution density function.

In order to account for skewness and tails' behavior, we considered the generalized Skew-t distribution by [50]. After estimating the moments' time series, we tested for long memory by using the nonparametric frequency-domain approach proposed by [40].

The results indicate that most of the S\&P500 stocks were characterized by a shortmemory conditional mean process and long memory in the variance, confirming the findings of earlier research on the topic.

In conclusion, our findings confirm that the nonparametric frequency-domain approach should be used in combination with classical time series methods for testing long memory.

Nevertheless, this paper adds noteworthy evidence with respect to the shape properties, finding that it was characterized by long-memory processes for most of the stock returns. As regards skewness, instead, the evidence is mixed. Therefore, we believe that further studies should be devoted to the analysis of conditional skewness.

Our findings are especially relevant in the context of asset allocation problems. Indeed, as noted by [32], predicting time-varying higher moments is crucial, since it allows for the so-called distribution timing, which is defined as the ability of using forecasts for moments up to the fourth one and is proved to generate significant incremental economic value to investors [32]. In this respect, if higher moments show long memory, it is possible to use appropriate statistical models for their prediction. Moreover, our findings represent a first step for the mathematical modeling of the stochastic behavior of conditional higher moments.

Author Contributions: Conceptualization, M.G. and D.P.; methodology, M.G. and D.P.; software, M.G. and D.P.; validation, M.G. and D.P.; formal analysis, M.G. and D.P.; data curation, M.G. and D.P.; writing-original draft preparation, M.G. and D.P.; writing-review and editing, M.G. and 
D.P.; visualization, M.G. and D.P. All authors have read and agreed to the published version of the manuscript.

Funding: This research study received no external funding.

Institutional Review Board Statement: Not applicable.

Informed Consent Statement: Not applicable.

Data Availability Statement: Not applicable.

Acknowledgments: The authors would like to thank Guest Editor Stefano Bonnini for his invitation to publish this feature paper in Mathematics. They also thank Raffaele Mattera for his valuable comments on the paper.

Conflicts of Interest: The authors declare no conflicts of interest.

\section{Appendix A}

Table A1. Long memory nonparametric test: results for stocks belonging to the Industrial sector.

\begin{tabular}{|c|c|c|c|c|c|c|c|c|c|}
\hline \multicolumn{2}{|c|}{ Stock } & \multicolumn{2}{|c|}{ Mean } & \multicolumn{2}{|c|}{ Variance } & \multicolumn{2}{|c|}{ Skewness } & \multicolumn{2}{|l|}{ Shape } \\
\hline ID & Ticker & Q-Stat & $p$-Value & Q-Stat & $p$-Value & Q-Stat & $p$-Value & Q-Stat & $p$-Value \\
\hline 2 & AAL & 19.39 & 0.00 & 2.60 & 0.52 & 106.72 & 0.00 & 834.80 & 0.00 \\
\hline 25 & ALK & 0.38 & 0.99 & 4.49 & 0.17 & 1.91 & 0.70 & 43.09 & 0.00 \\
\hline 27 & ALLE & 0.05 & 1.00 & 17.02 & 0.00 & 1.79 & 0.73 & 280.22 & 0.00 \\
\hline 32 & AME & 0.19 & 1.00 & 1.95 & 0.69 & 0.03 & 1.00 & 846.44 & 0.00 \\
\hline 41 & AOS & 0.47 & 0.99 & 30.05 & 0.00 & 8.41 & 0.01 & 514.98 & 0.00 \\
\hline 55 & BA & 2.63 & 0.51 & 341.48 & 0.00 & 2.17 & 0.63 & 122.04 & 0.00 \\
\hline 76 & CARR & 1197.31 & 0.00 & 0.26 & 1.00 & 79.86 & 0.00 & 43.25 & 0.00 \\
\hline 77 & CAT & 356.69 & 0.00 & 104.17 & 0.00 & 1.87 & 0.71 & $14,056.86$ & 0.00 \\
\hline 90 & CHRW & 0.39 & 0.99 & 8.09 & 0.01 & 0.42 & 0.99 & $4,676,493.63$ & 0.00 \\
\hline 100 & CMI & 134.92 & 0.00 & 6.03 & 0.06 & 4.50 & 0.17 & 79.86 & 0.00 \\
\hline 110 & CPRT & 0.70 & 0.97 & 39.95 & 0.00 & 164.06 & 0.00 & 897.75 & 0.00 \\
\hline 113 & CSX & 2.00 & 0.68 & 2.97 & 0.43 & 101.93 & 0.00 & 988.16 & 0.00 \\
\hline 114 & CTAS & 0.22 & 1.00 & 8.75 & 0.01 & 1.72 & 0.75 & 9.61 & 0.00 \\
\hline 123 & DAL & 2.23 & 0.62 & 16.82 & 0.00 & 23.26 & 0.00 & 2.23 & 0.61 \\
\hline 125 & $\mathrm{DE}$ & 0.38 & 0.99 & 16.61 & 0.00 & 569.78 & 0.00 & $3,944,620.35$ & 0.00 \\
\hline 137 & DOV & 2.88 & 0.45 & 7.12 & 0.03 & 2.65 & 0.51 & $37,981,286.37$ & 0.00 \\
\hline 152 & EFX & 0.13 & 1.00 & 9.44 & 0.00 & 3.03 & 0.42 & 5418.77 & 0.00 \\
\hline 156 & EMR & 0.88 & 0.94 & 25.13 & 0.00 & 1.93 & 0.70 & 53.61 & 0.00 \\
\hline 163 & ETN & 0.87 & 0.94 & 14.28 & 0.00 & 2.16 & 0.63 & $25,829.63$ & 0.00 \\
\hline 169 & EXPD & 0.44 & 0.99 & 9.16 & 0.01 & 164.38 & 0.00 & 205.36 & 0.00 \\
\hline 174 & FAST & 0.12 & 1.00 & 2269.57 & 0.00 & 25.30 & 0.00 & $3,294,249,843,584,581.00$ & 0.00 \\
\hline 176 & FBHS & 7.46 & 0.02 & 6.12 & 0.06 & 6.33 & 0.05 & 4847.75 & 0.00 \\
\hline 178 & FDX & 1.60 & 0.78 & 10.16 & 0.00 & 0.34 & 0.99 & $153,756,604,383,877,056.00$ & 0.00 \\
\hline 192 & FTV & 0.16 & 1.00 & 293.62 & 0.00 & 1.84 & 0.72 & 26.71 & 0.00 \\
\hline 193 & GD & 3.86 & 0.26 & 0.64 & 0.97 & 0.14 & 1.00 & 37.02 & 0.00 \\
\hline 194 & GE & 0.88 & 0.94 & 50.91 & 0.00 & 209.29 & 0.00 & 28.00 & 0.00 \\
\hline 200 & GNRC & 4.34 & 0.19 & 6.39 & 0.05 & 3.45 & 0.33 & $290,470,898.76$ & 0.00 \\
\hline 208 & GWW & 0.04 & 1.00 & 2.94 & 0.44 & 0.09 & 1.00 & $253,267.41$ & 0.00 \\
\hline 218 & HII & 0.72 & 0.96 & 8.61 & 0.01 & 9.49 & 0.00 & 8134.98 & 0.00 \\
\hline 221 & $\mathrm{HON}$ & 0.05 & 1.00 & 2.43 & 0.56 & 1.84 & 0.72 & 3589.42 & 0.00 \\
\hline 229 & HWM & 821.51 & 0.00 & 7.03 & 0.03 & 71.74 & 0.00 & $38,025.97$ & 0.00 \\
\hline 233 & IEX & 1.88 & 0.71 & 3.95 & 0.25 & 42.20 & 0.00 & 2202.18 & 0.00 \\
\hline 237 & INFO & 0.45 & 0.99 & 140.01 & 0.00 & 14.80 & 0.00 & $95,396.69$ & 0.00 \\
\hline 244 & IR & 692.97 & 0.00 & 10.59 & 0.00 & 7.73 & 0.02 & 8827.31 & 0.00 \\
\hline 248 & ITW & 0.86 & 0.94 & 49.75 & 0.00 & 479.58 & 0.00 & 90.31 & 0.00 \\
\hline 250 & $\mathrm{~J}$ & 1.80 & 0.73 & 2.47 & 0.55 & 6.91 & 0.03 & $73,930.54$ & 0.00 \\
\hline 251 & JBHT & 0.08 & 1.00 & 9.62 & 0.00 & 2.10 & 0.65 & $4,100,854.84$ & 0.00 \\
\hline 252 & $\mathrm{JCI}$ & 0.54 & 0.98 & 1.32 & 0.85 & 53.17 & 0.00 & $49,691.69$ & 0.00 \\
\hline 268 & KSU & 1.50 & 0.81 & 40.85 & 0.00 & 10.10 & 0.00 & $37,086,905.93$ & 0.00 \\
\hline 271 & LDOS & 9.30 & 0.00 & 428.28 & 0.00 & 9.56 & 0.00 & 4078.81 & 0.00 \\
\hline 275 & LHX & 1.24 & 0.87 & 5.54 & 0.09 & 0.21 & 1.00 & 106.47 & 0.00 \\
\hline 279 & LMT & 3.15 & 0.39 & 3.34 & 0.35 & 67.94 & 0.00 & $18,479.57$ & 0.00 \\
\hline 285 & LUV & 533.76 & 0.00 & 4.42 & 0.18 & 0.05 & 1.00 & $607,402.71$ & 0.00 \\
\hline 293 & MAS & 1.42 & 0.83 & 1.87 & 0.71 & 0.20 & 1.00 & 9.37 & 0.00 \\
\hline 307 & MMM & 1.27 & 0.86 & 17.90 & 0.00 & 993.30 & 0.00 & 488.30 & 0.00 \\
\hline 331 & NLSN & 5.41 & 0.09 & 5.99 & 0.06 & 49.15 & 0.00 & $14,949.03$ & 0.00 \\
\hline 332 & NOC & 1.81 & 0.73 & 0.56 & 0.98 & 19.71 & 0.00 & $30,549.28$ & 0.00 \\
\hline 336 & NSC & 1.53 & 0.80 & 24.79 & 0.00 & 1.82 & 0.73 & $19,050,673.08$ & 0.00 \\
\hline 347 & ODFL & 1.40 & 0.83 & 6.86 & 0.03 & 8.69 & 0.01 & 51.17 & 0.00 \\
\hline 352 & OTIS & 4.88 & 0.14 & 0.11 & 1.00 & 2.61 & 0.52 & 16.14 & 0.00 \\
\hline 357 & PCAR & 0.37 & 0.99 & 1.85 & 0.72 & 222.78 & 0.00 & $67,386,429.24$ & 0.00 \\
\hline 366 & $\mathrm{PH}$ & 7.91 & 0.01 & 27.54 & 0.00 & 0.51 & 0.98 & 521.89 & 0.00 \\
\hline 373 & PNR & 1.07 & 0.91 & 165.99 & 0.00 & 516.89 & 0.00 & 195.39 & 0.00 \\
\hline 384 & PWR & 1.14 & 0.89 & 0.88 & 0.94 & 0.71 & 0.96 & 22.61 & 0.00 \\
\hline
\end{tabular}


Table A1. Cont.

\begin{tabular}{|c|c|c|c|c|c|c|c|c|c|}
\hline \multicolumn{2}{|c|}{ Stock } & \multicolumn{2}{|c|}{ Mean } & \multicolumn{2}{|c|}{ Variance } & \multicolumn{2}{|c|}{ Skewness } & \multicolumn{2}{|c|}{ Shape } \\
\hline ID & Ticker & Q-Stat & $p$-Value & Q-Stat & $p$-Value & Q-Stat & $p$-Value & Q-Stat & $p$-Value \\
\hline 394 & RHI & 52.18 & 0.00 & 2.97 & 0.43 & 0.21 & 1.00 & $83,337.44$ & 0.00 \\
\hline 398 & ROK & 0.91 & 0.94 & 2.02 & 0.67 & 0.44 & 0.99 & 22.88 & 0.00 \\
\hline 399 & ROL & 0.47 & 0.99 & 41.18 & 0.00 & 35.74 & 0.00 & $37,674,798,980.54$ & 0.00 \\
\hline 400 & ROP & 0.25 & 1.00 & 16.68 & 0.00 & 1265.39 & 0.00 & 4782.85 & 0.00 \\
\hline 402 & RSG & 0.95 & 0.93 & 1.63 & 0.78 & 2.28 & 0.60 & $293,363,986.16$ & 0.00 \\
\hline 403 & RTX & 2.62 & 0.51 & 56.57 & 0.00 & 137.65 & 0.00 & $28,007.85$ & 0.00 \\
\hline 412 & SNA & 0.32 & 1.00 & 7.24 & 0.02 & 772.21 & 0.00 & $1,169,932.21$ & 0.00 \\
\hline 422 & SWK & 0.77 & 0.96 & 112.95 & 0.00 & 0.23 & 1.00 & 93.82 & 0.00 \\
\hline 429 & TDG & 0.22 & 1.00 & 373.46 & 0.00 & 4.84 & 0.14 & 398.92 & 0.00 \\
\hline 430 & TDY & 0.37 & 0.99 & 68.68 & 0.00 & 0.89 & 0.94 & 609.31 & 0.00 \\
\hline 446 & $\mathrm{TT}$ & 2.20 & 0.62 & 2.19 & 0.63 & 18.73 & 0.00 & 51.96 & 0.00 \\
\hline 450 & TXT & 1.24 & 0.87 & 14.92 & 0.00 & 0.13 & 1.00 & 403.95 & 0.00 \\
\hline 454 & UAL & 0.39 & 0.99 & 29.73 & 0.00 & 518.49 & 0.00 & 60.79 & 0.00 \\
\hline 460 & UNP & 1.09 & 0.90 & 15.96 & 0.00 & 2.87 & 0.45 & $12,243.78$ & 0.00 \\
\hline 461 & UPS & 0.56 & 0.98 & 4.22 & 0.21 & 8.20 & 0.01 & $12,253.66$ & 0.00 \\
\hline 462 & URI & 2.84 & 0.46 & 23.39 & 0.00 & 74.23 & 0.00 & $26,727.20$ & 0.00 \\
\hline 470 & VRSK & 1.49 & 0.81 & 22.06 & 0.00 & 16.19 & 0.00 & $1,922,017.73$ & 0.00 \\
\hline 476 & WAB & 2.49 & 0.55 & 3.57 & 0.31 & 0.25 & 1.00 & 1.62 & 0.78 \\
\hline 485 & WM & 0.35 & 0.99 & 3.62 & 0.30 & 2.46 & 0.55 & $32,050,262,904.22$ & 0.00 \\
\hline 498 & XYL & 3.62 & 0.30 & 6.61 & 0.04 & 8.27 & 0.01 & $22,587.86$ & 0.00 \\
\hline
\end{tabular}

Table A2. Long-memory nonparametric test: results for stocks belonging to the Health Care sector.

\begin{tabular}{|c|c|c|c|c|c|c|c|c|c|}
\hline \multicolumn{2}{|c|}{ Stock } & \multicolumn{2}{|c|}{ Mean } & \multicolumn{2}{|c|}{ Variance } & \multicolumn{2}{|c|}{ Skewness } & \multicolumn{2}{|l|}{ Shape } \\
\hline ID & Ticker & Q-Stat & $p$-Value & Q-Stat & $p$-Value & Q-Stat & $p$-Value & Q-Stat & $p$-Value \\
\hline 1 & A & 0.97 & 0.93 & 6.12 & 0.06 & 105.67 & 0.00 & $841,079,388.58$ & 0.00 \\
\hline 5 & ABBV & 24.86 & 0.00 & 43.11 & 0.00 & 6.53 & 0.04 & 3682.11 & 0.00 \\
\hline 6 & $\mathrm{ABC}$ & 0.52 & 0.98 & 10.24 & 0.00 & 108.28 & 0.00 & 8341.98 & 0.00 \\
\hline 7 & ABMD & 0.53 & 0.98 & 15.49 & 0.00 & 109.00 & 0.00 & 25.71 & 0.00 \\
\hline 8 & ABT & 1.67 & 0.76 & 60.63 & 0.00 & 173.47 & 0.00 & $190,949,740.36$ & 0.00 \\
\hline 24 & ALGN & 181.94 & 0.00 & 251.73 & 0.00 & 0.78 & 0.95 & $4,750,3316,609,669.00$ & 0.00 \\
\hline 28 & ALXN & 0.11 & 1.00 & 1004.47 & 0.00 & 753.84 & 0.00 & $15,279.64$ & 0.00 \\
\hline 33 & AMGN & 1.56 & 0.79 & 8.80 & 0.01 & 75.27 & 0.00 & 420.89 & 0.00 \\
\hline 39 & ANTM & 2.83 & 0.46 & 34.58 & 0.00 & 0.87 & 0.94 & 2151.78 & 0.00 \\
\hline 57 & BAX & 2.61 & 0.51 & 11.83 & 0.00 & 23.20 & 0.00 & $10,111.26$ & 0.00 \\
\hline 59 & $\mathrm{BDX}$ & 0.77 & 0.96 & 2.58 & 0.52 & 4.11 & 0.22 & 9.40 & 0.00 \\
\hline 61 & BIIB & 0.00 & 1.00 & 4.87 & 0.14 & 20.11 & 0.00 & 1319.21 & 0.00 \\
\hline 62 & $\mathrm{BIO}$ & 3.32 & 0.36 & 13.66 & 0.00 & 123.32 & 0.00 & $16,644,212,815,952,544.00$ & 0.00 \\
\hline 68 & $\mathrm{BMY}$ & 0.24 & 1.00 & 13.71 & 0.00 & 0.70 & 0.97 & $642,853,886,634,605.00$ & 0.00 \\
\hline 70 & BSX & 0.28 & 1.00 & 0.00 & 1.00 & 25.14 & 0.00 & 0.24 & 1.00 \\
\hline 75 & $\mathrm{CAH}$ & 0.34 & 0.99 & 7.70 & 0.02 & 0.38 & 0.99 & $135,912,232,695.16$ & 0.00 \\
\hline 86 & CERN & 0.01 & 1.00 & 14.02 & 0.00 & 0.88 & 0.94 & $140,223,765,921.39$ & 0.00 \\
\hline 92 & CI & 0.55 & 0.98 & 227.47 & 0.00 & 2.90 & 0.45 & 1469.98 & 0.00 \\
\hline 102 & CNC & 0.51 & 0.98 & 39.77 & 0.00 & 3.23 & 0.37 & $142,257.20$ & 0.00 \\
\hline 106 & $\mathrm{COO}$ & 0.29 & 1.00 & 6.48 & 0.04 & 1.69 & 0.76 & $47,335,590.74$ & 0.00 \\
\hline 115 & CTLT & 2.91 & 0.44 & 27.19 & 0.00 & 8.53 & 0.01 & $152,172,724.91$ & 0.00 \\
\hline 119 & CVS & 2.63 & 0.51 & 5.63 & 0.08 & 0.56 & 0.98 & 1221.33 & 0.00 \\
\hline 128 & DGX & 1.81 & 0.73 & 4.28 & 0.20 & 0.90 & 0.94 & $96,007,333.51$ & 0.00 \\
\hline 130 & DHR & 0.66 & 0.97 & 12.23 & 0.00 & 2.39 & 0.57 & $26,723.56$ & 0.00 \\
\hline 144 & DVA & 0.00 & 1.00 & 120.36 & 0.00 & 10.71 & 0.00 & $186,548.11$ & 0.00 \\
\hline 147 & DXCM & 0.20 & 1.00 & 3.42 & 0.34 & 2.35 & 0.58 & 5442.55 & 0.00 \\
\hline 167 & EW & 1.43 & 0.83 & 22.52 & 0.00 & 1.00 & 0.92 & $20,838.72$ & 0.00 \\
\hline 195 & GILD & 0.08 & 1.00 & 23.89 & 0.00 & 30.95 & 0.00 & $1,055,355.57$ & 0.00 \\
\hline 213 & HCA & 0.13 & 1.00 & 16.12 & 0.00 & 185.60 & 0.00 & 1.88 & 0.71 \\
\hline 220 & HOLX & 1.93 & 0.70 & 2.18 & 0.63 & 1.51 & 0.81 & 148.08 & 0.00 \\
\hline 225 & HSIC & 0.75 & 0.96 & 5.69 & 0.08 & 35.08 & 0.00 & 114.84 & 0.00 \\
\hline 228 & HUM & 2.92 & 0.44 & 17.91 & 0.00 & 283.55 & 0.00 & 22.55 & 0.00 \\
\hline 232 & IDXX & 1.40 & 0.83 & 59.24 & 0.00 & 11.88 & 0.00 & $997,701.95$ & 0.00 \\
\hline 235 & ILMN & 0.17 & 1.00 & 48.87 & 0.00 & 141.30 & 0.00 & $82,783,148,014,973,681,664.00$ & 0.00 \\
\hline 236 & INCY & 0.21 & 1.00 & 668.29 & 0.00 & 1.34 & 0.85 & $556,364,652.25$ & 0.00 \\
\hline 243 & IQV & 2.84 & 0.46 & 49.71 & 0.00 & 67.13 & 0.00 & 2215.75 & 0.00 \\
\hline 246 & ISRG & 1.04 & 0.91 & 0.18 & 1.00 & 544.34 & 0.00 & 0.05 & 1.00 \\
\hline 254 & JNJ & 1.59 & 0.78 & 2.23 & 0.61 & 103.32 & 0.00 & 1016.69 & 0.00 \\
\hline 274 & LH & 0.70 & 0.97 & 345.63 & 0.00 & 2.09 & 0.65 & 130.21 & 0.00 \\
\hline 278 & LLY & 0.22 & 1.00 & 63.67 & 0.00 & 194.52 & 0.00 & $747,225.92$ & 0.00 \\
\hline 296 & MCK & 0.61 & 0.98 & 45.09 & 0.00 & 2.69 & 0.50 & 6831.38 & 0.00 \\
\hline 299 & MDT & 1.79 & 0.73 & 0.40 & 0.99 & 121.33 & 0.00 & $1,640,410,921.56$ & 0.00 \\
\hline 313 & MRK & 0.95 & 0.93 & 8.50 & 0.01 & 168.78 & 0.00 & 0.13 & 1.00 \\
\hline 320 & MTD & 3.11 & 0.40 & 5.95 & 0.06 & 40.66 & 0.00 & $9,601,115.42$ & 0.00 \\
\hline 362 & PFE & 5.26 & 0.10 & 4.35 & 0.19 & 110.47 & 0.00 & 151.17 & 0.00 \\
\hline 369 & PKI & 0.02 & 1.00 & 6.81 & 0.03 & 14.71 & 0.00 & $12,416.89$ & 0.00 \\
\hline 378 & PRGO & 1.15 & 0.89 & 3.42 & 0.34 & 102.30 & 0.00 & $11,780.07$ & 0.00 \\
\hline 392 & REGN & 1.06 & 0.91 & 59.60 & 0.00 & 44.37 & 0.00 & 0.01 & 1.00 \\
\hline 397 & RMD & 0.66 & 0.97 & 3.93 & 0.25 & 1.90 & 0.70 & $16,150,481,436.89$ & 0.00 \\
\hline 418 & STE & 0.04 & 1.00 & 35.83 & 0.00 & 1.70 & 0.76 & 1452.73 & 0.00 \\
\hline
\end{tabular}


Table A2. Cont.

\begin{tabular}{|c|c|c|c|c|c|c|c|c|c|}
\hline \multicolumn{2}{|c|}{ Stock } & \multicolumn{2}{|c|}{ Mean } & \multicolumn{2}{|c|}{ Variance } & \multicolumn{2}{|c|}{ Skewness } & \multicolumn{2}{|l|}{ Shape } \\
\hline ID & Ticker & Q-Stat & $p$-Value & Q-Stat & $p$-Value & Q-Stat & $p$-Value & Q-Stat & $p$-Value \\
\hline 425 & SYK & 0.04 & 1.00 & 34.84 & 0.00 & 150.53 & 0.00 & 8744.73 & 0.00 \\
\hline 434 & TFX & 0.94 & 0.93 & 15.40 & 0.00 & 2.55 & 0.53 & 9592.07 & 0.00 \\
\hline 437 & TMO & 0.41 & 0.99 & 72.37 & 0.00 & 0.20 & 1.00 & 844.85 & 0.00 \\
\hline 456 & UHS & 0.03 & 1.00 & 1.24 & 0.87 & 0.32 & 1.00 & 0.28 & 1.00 \\
\hline 458 & UNH & 0.73 & 0.96 & 4.74 & 0.15 & 320.08 & 0.00 & 437.51 & 0.00 \\
\hline 472 & VRTX & 0.19 & 1.00 & 3.58 & 0.31 & 1.25 & 0.87 & $1,838,838,485,805,622,347,462,806.00$ & 0.00 \\
\hline 474 & VTRS & 1.26 & 0.87 & 39.47 & 0.00 & 12.60 & 0.00 & $31,779,637,199.41$ & 0.00 \\
\hline 477 & WAT & 0.47 & 0.99 & 23.14 & 0.00 & 7.15 & 0.03 & $843,850.13$ & 0.00 \\
\hline 490 & WST & 1.15 & 0.89 & 3.79 & 0.27 & 2.44 & 0.56 & 552.13 & 0.00 \\
\hline 497 & XRAY & 0.46 & 0.99 & 9.83 & 0.00 & 118.46 & 0.00 & $17,242,480.93$ & 0.00 \\
\hline 500 & ZBH & 6.88 & 0.03 & 5.70 & 0.08 & 40.00 & 0.00 & $55,839.61$ & 0.00 \\
\hline 503 & ZTS & 5.54 & 0.09 & 39.06 & 0.00 & 21.86 & 0.00 & $29,206.43$ & 0.00 \\
\hline
\end{tabular}

Table A3. Long-memory nonparametric test: results for stocks belonging to the Information Technology sector.

\begin{tabular}{|c|c|c|c|c|c|c|c|c|c|}
\hline \multicolumn{2}{|c|}{ Stock } & \multicolumn{2}{|c|}{ Mean } & \multicolumn{2}{|c|}{ Variance } & \multicolumn{2}{|c|}{ Skewness } & \multicolumn{2}{|l|}{ Shape } \\
\hline ID & Ticker & Q-Stat & $p$-Value & Q-Stat & $p$-Value & Q-Stat & $p$-Value & Q-Stat & $p$-Value \\
\hline 4 & AAPL & 0.27 & 1.00 & 14.42 & 0.00 & 2.65 & 0.51 & $806,704.86$ & 0.00 \\
\hline 9 & $\mathrm{ACN}$ & 0.05 & 1.00 & 4.13 & 0.22 & 28.10 & 0.00 & $81,229.80$ & 0.00 \\
\hline 10 & ADBE & 1.18 & 0.88 & 6.09 & 0.06 & 44.04 & 0.00 & 2215.62 & 0.00 \\
\hline 11 & ADI & 0.59 & 0.98 & 28.09 & 0.00 & 5.54 & 0.09 & 3465.60 & 0.00 \\
\hline 13 & ADP & 0.07 & 1.00 & 37.67 & 0.00 & 3.10 & 0.40 & 621.40 & 0.00 \\
\hline 14 & ADSK & 1.20 & 0.88 & 2.47 & 0.55 & 0.42 & 0.99 & 555.46 & 0.00 \\
\hline 22 & AKAM & 0.93 & 0.93 & 5.65 & 0.08 & 17.18 & 0.00 & 0.00 & 1.00 \\
\hline 29 & AMAT & 14.95 & 0.00 & 7.84 & 0.02 & 158.39 & 0.00 & 162.53 & 0.00 \\
\hline 31 & AMD & 235.71 & 0.00 & 98.95 & 0.00 & 7.44 & 0.02 & $857,785,903,381,856.00$ & 0.00 \\
\hline 37 & ANET & 0.46 & 0.99 & 21.05 & 0.00 & 29.95 & 0.00 & 2.49 & 0.55 \\
\hline 38 & ANSS & 0.04 & 1.00 & 10.50 & 0.00 & 0.16 & 1.00 & 976.27 & 0.00 \\
\hline 44 & APH & 2.83 & 0.46 & 3.93 & 0.25 & 5877.73 & 0.00 & $200,425,249,067.64$ & 0.00 \\
\hline 50 & AVGO & 1.94 & 0.69 & 3.22 & 0.38 & 5.50 & 0.09 & 3029.97 & 0.00 \\
\hline 69 & BR & 1.45 & 0.82 & 0.54 & 0.98 & 5.31 & 0.10 & 3.73 & 0.28 \\
\hline 83 & CDNS & 32.93 & 0.00 & 0.82 & 0.95 & 6.41 & 0.05 & 574.11 & 0.00 \\
\hline 84 & CDW & 4.09 & 0.22 & 13.50 & 0.00 & 34.54 & 0.00 & 168.15 & 0.00 \\
\hline 111 & CRM & 1.18 & 0.88 & 1.88 & 0.71 & 3.57 & 0.31 & $274,433.66$ & 0.00 \\
\hline 112 & $\mathrm{CSCO}$ & 1.17 & 0.89 & 69.56 & 0.00 & 2.37 & 0.58 & 27.53 & 0.00 \\
\hline 116 & CTSH & 1.52 & 0.80 & 15.92 & 0.00 & 326.22 & 0.00 & $94,814.79$ & 0.00 \\
\hline 118 & CTXS & 0.45 & 0.99 & 7.38 & 0.02 & 0.03 & 1.00 & $217,336,217.27$ & 0.00 \\
\hline 146 & DXC & 2.62 & 0.51 & 1113.92 & 0.00 & 0.10 & 1.00 & 5938.11 & 0.00 \\
\hline 157 & ENPH & 218.99 & 0.00 & 326.29 & 0.00 & 337.15 & 0.00 & 1785.69 & 0.00 \\
\hline 180 & FFIV & 7.17 & 0.03 & 0.75 & 0.96 & 35.92 & 0.00 & 0.01 & 1.00 \\
\hline 181 & FIS & 0.33 & 1.00 & 120.28 & 0.00 & 2.28 & 0.60 & 63.67 & 0.00 \\
\hline 182 & FISV & 0.02 & 1.00 & 69.16 & 0.00 & 1.49 & 0.81 & 134.65 & 0.00 \\
\hline 184 & FLIR & 2.06 & 0.66 & 5.32 & 0.10 & 2.92 & 0.44 & $28,464.51$ & 0.00 \\
\hline 185 & FLT & 0.37 & 0.99 & 17.82 & 0.00 & 3.55 & 0.31 & 187.63 & 0.00 \\
\hline 191 & FTNT & 4.32 & 0.19 & 0.71 & 0.96 & 12.76 & 0.00 & 0.01 & 1.00 \\
\hline 198 & GLW & 1.26 & 0.87 & 21.97 & 0.00 & 5.92 & 0.07 & $26,897.60$ & 0.00 \\
\hline 204 & GPN & 0.12 & 1.00 & 35.81 & 0.00 & 17.03 & 0.00 & 48.40 & 0.00 \\
\hline 222 & HPE & 1.08 & 0.91 & 10.28 & 0.00 & 0.60 & 0.98 & 21.89 & 0.00 \\
\hline 223 & $\mathrm{HPQ}$ & 3.71 & 0.28 & 18.75 & 0.00 & 296.60 & 0.00 & 2770.01 & 0.00 \\
\hline 230 & IBM & 0.74 & 0.96 & 9.21 & 0.01 & 2.33 & 0.59 & 9634.67 & 0.00 \\
\hline 238 & INTC & 0.30 & 1.00 & 38.78 & 0.00 & 0.14 & 1.00 & $35,716.06$ & 0.00 \\
\hline 239 & INTU & 0.71 & 0.96 & 30.64 & 0.00 & 1.37 & 0.84 & $1,231,879.28$ & 0.00 \\
\hline 242 & IPGP & 685.87 & 0.00 & 4.55 & 0.17 & 1.76 & 0.74 & 0.00 & 1.00 \\
\hline 247 & IT & 0.02 & 1.00 & 4.47 & 0.18 & 82.55 & 0.00 & 33.71 & 0.00 \\
\hline 253 & JKHY & 0.05 & 1.00 & 4.41 & 0.18 & 249.09 & 0.00 & $15,049.62$ & 0.00 \\
\hline 255 & JNPR & 0.70 & 0.97 & 6.97 & 0.03 & 408.45 & 0.00 & 4.78 & 0.14 \\
\hline 259 & KEYS & 2.75 & 0.48 & 37.70 & 0.00 & 7.50 & 0.02 & 4594.59 & 0.00 \\
\hline 262 & KLAC & 7.80 & 0.02 & 1.71 & 0.75 & 8.90 & 0.01 & $12,236,802,372.94$ & 0.00 \\
\hline 283 & LRCX & 3.50 & 0.32 & 0.91 & 0.94 & 117.59 & 0.00 & 4283.25 & 0.00 \\
\hline 290 & MA & 0.27 & 1.00 & 4.14 & 0.22 & 1.43 & 0.83 & $365,171.12$ & 0.00 \\
\hline 295 & MCHP & 3.27 & 0.37 & 27.67 & 0.00 & 64.60 & 0.00 & $371,984.08$ & 0.00 \\
\hline 312 & MPWR & 0.35 & 0.99 & 5.15 & 0.11 & 122.82 & 0.00 & 84.93 & 0.00 \\
\hline 317 & MSFT & 0.41 & 0.99 & 54.36 & 0.00 & 225.41 & 0.00 & $7,082,818.52$ & 0.00 \\
\hline 318 & MSI & 0.37 & 0.99 & 95.94 & 0.00 & 28.33 & 0.00 & $201,336,442,869.61$ & 0.00 \\
\hline 321 & MU & 950.20 & 0.00 & 3474.96 & 0.00 & 19.31 & 0.00 & $24,891.98$ & 0.00 \\
\hline 322 & MXIM & 1.76 & 0.74 & 6.18 & 0.05 & 771.23 & 0.00 & 458.84 & 0.00 \\
\hline 330 & NLOK & 7.41 & 0.02 & 54.26 & 0.00 & 13.14 & 0.00 & $163,613.06$ & 0.00 \\
\hline 334 & NOW & 0.78 & 0.96 & 0.09 & 1.00 & 748.15 & 0.00 & 793.38 & 0.00 \\
\hline 337 & NTAP & 0.88 & 0.94 & 5.50 & 0.09 & 0.32 & 1.00 & $5,398,359,121,234.75$ & 0.00 \\
\hline 340 & NVDA & 2.15 & 0.64 & 1.32 & 0.85 & 4.58 & 0.16 & 113.50 & 0.00 \\
\hline 345 & NXPI & 4.35 & 0.19 & 10.40 & 0.00 & 16.08 & 0.00 & $649,872.58$ & 0.00 \\
\hline 350 & ORCL & 0.60 & 0.98 & 38.60 & 0.00 & 47.89 & 0.00 & $839,023.77$ & 0.00 \\
\hline 354 & PAYC & 0.29 & 1.00 & 8.83 & 0.01 & 46.70 & 0.00 & 8.86 & 0.01 \\
\hline 355 & PAYX & 0.60 & 0.98 & 44.50 & 0.00 & 4.11 & 0.22 & 796.33 & 0.00 \\
\hline
\end{tabular}


Table A3. Cont.

\begin{tabular}{|c|c|c|c|c|c|c|c|c|c|}
\hline \multicolumn{2}{|c|}{ Stock } & \multicolumn{2}{|c|}{ Mean } & \multicolumn{2}{|c|}{ Variance } & \multicolumn{2}{|c|}{ Skewness } & \multicolumn{2}{|l|}{ Shape } \\
\hline ID & Ticker & Q-Stat & $p$-Value & Q-Stat & $p$-Value & Q-Stat & $p$-Value & Q-Stat & $p$-Value \\
\hline 382 & PTC & 25.18 & 0.00 & 54.22 & 0.00 & 20.36 & 0.00 & 9823.37 & 0.00 \\
\hline 386 & PYPL & 490.43 & 0.00 & 100.24 & 0.00 & 5.81 & 0.07 & $23,985.04$ & 0.00 \\
\hline 387 & QCOM & 0.15 & 1.00 & 15.87 & 0.00 & 7.12 & 0.03 & $12,228.67$ & 0.00 \\
\hline 388 & QRVO & 0.36 & 0.99 & 26.33 & 0.00 & 76.56 & 0.00 & $105,343.95$ & 0.00 \\
\hline 413 & SNPS & 0.10 & 1.00 & 24.63 & 0.00 & 8.51 & 0.01 & $22,961.41$ & 0.00 \\
\hline 420 & STX & 188.36 & 0.00 & 271.63 & 0.00 & 3.26 & 0.37 & $216,750,037,595.95$ & 0.00 \\
\hline 423 & SWKS & 0.75 & 0.96 & 13.35 & 0.00 & 3.04 & 0.41 & $78,373,584,126,967,520.00$ & 0.00 \\
\hline 431 & TEL & 1.84 & 0.72 & 4.38 & 0.19 & 4.26 & 0.20 & 601.72 & 0.00 \\
\hline 432 & TER & 4.85 & 0.14 & 5.51 & 0.09 & 362.28 & 0.00 & $57,117.61$ & 0.00 \\
\hline 440 & TRMB & 1.82 & 0.73 & 1.06 & 0.91 & 2.22 & 0.62 & 8488.83 & 0.00 \\
\hline 449 & TXN & 4.24 & 0.20 & 229.26 & 0.00 & 18.11 & 0.00 & $85,883.74$ & 0.00 \\
\hline 451 & TYL & 0.21 & 1.00 & 21.45 & 0.00 & 29.17 & 0.00 & $82,591.72$ & 0.00 \\
\hline 464 & $\mathrm{~V}$ & 0.14 & 1.00 & 23.16 & 0.00 & 17.49 & 0.00 & $782,385.57$ & 0.00 \\
\hline 471 & VRSN & 0.55 & 0.98 & 15.45 & 0.00 & 124.20 & 0.00 & $778,422.22$ & 0.00 \\
\hline 479 & WDC & 523.80 & 0.00 & 9.77 & 0.00 & 41.42 & 0.00 & $87,334,393.43$ & 0.00 \\
\hline 491 & WU & 0.72 & 0.96 & 6.64 & 0.04 & 1.21 & 0.88 & $16,968,419.06$ & 0.00 \\
\hline 495 & XLNX & 2.61 & 0.52 & 15.46 & 0.00 & 5.50 & 0.09 & $10,654,035.18$ & 0.00 \\
\hline 501 & ZBRA & 0.46 & 0.99 & 40.09 & 0.00 & 1.44 & 0.82 & 8746.86 & 0.00 \\
\hline
\end{tabular}

Table A4. Long-memory nonparametric test: results for stocks belonging to the Communication Services sector.

\begin{tabular}{|c|c|c|c|c|c|c|c|c|c|}
\hline \multicolumn{2}{|c|}{ Stock } & \multicolumn{2}{|c|}{ Mean } & \multicolumn{2}{|c|}{ Variance } & \multicolumn{2}{|c|}{ Skewness } & \multicolumn{2}{|l|}{ Shape } \\
\hline ID & Ticker & Q-Stat & $p$-Value & Q-Stat & $p$-Value & Q-Stat & $p$-Value & Q-Stat & $p$-Value \\
\hline 48 & ATVI & 0.17 & 1.00 & 12.54 & 0.00 & 5.67 & 0.08 & $448,344.09$ & 0.00 \\
\hline 91 & CHTR & 1.58 & 0.79 & 74.07 & 0.00 & 93.26 & 0.00 & $2,807,626,133.76$ & 0.00 \\
\hline 97 & CMCSA & 0.08 & 1.00 & 12.87 & 0.00 & 3.87 & 0.26 & 9419.82 & 0.00 \\
\hline 131 & DIS & 0.00 & 1.00 & 6.65 & 0.04 & 4.14 & 0.22 & 9.64 & 0.00 \\
\hline 132 & DISCA & 4.21 & 0.21 & 23.46 & 0.00 & 35.27 & 0.00 & 1432.35 & 0.00 \\
\hline 133 & DISCK & 4.67 & 0.16 & 12.85 & 0.00 & 59.46 & 0.00 & $14,352.55$ & 0.00 \\
\hline 134 & DISH & 2.77 & 0.48 & 9.38 & 0.00 & 5.48 & 0.09 & 13.04 & 0.00 \\
\hline 148 & EA & 6.35 & 0.05 & 17.39 & 0.00 & 0.21 & 1.00 & 91.69 & 0.00 \\
\hline 175 & $\mathrm{FB}$ & 0.35 & 0.99 & 0.23 & 1.00 & 10.47 & 0.00 & $879,304,248,858,196,049,920.00$ & 0.00 \\
\hline 187 & FOX & 12.24 & 0.00 & 251.00 & 0.00 & 16.34 & 0.00 & 48.71 & 0.00 \\
\hline 188 & FOXA & 9.38 & 0.00 & 234.26 & 0.00 & 3.90 & 0.25 & 63.24 & 0.00 \\
\hline 201 & GOOG & 0.57 & 0.98 & 47.59 & 0.00 & 7.98 & 0.01 & 196.52 & 0.00 \\
\hline 202 & GOOGL & 0.96 & 0.93 & 61.39 & 0.00 & 8.02 & 0.01 & 204.77 & 0.00 \\
\hline 241 & IPG & 0.31 & 1.00 & 0.20 & 1.00 & 0.18 & 1.00 & 833.91 & 0.00 \\
\hline 284 & LUMN & 3.38 & 0.34 & 4.99 & 0.13 & 0.62 & 0.97 & $21,663.30$ & 0.00 \\
\hline 289 & LYV & 1.77 & 0.74 & 87.10 & 0.00 & 22.53 & 0.00 & $1,558,205.32$ & 0.00 \\
\hline 327 & NFLX & 0.52 & 0.98 & 44.82 & 0.00 & 33.86 & 0.00 & 5081.28 & 0.00 \\
\hline 343 & NWS & 2.27 & 0.60 & 112.28 & 0.00 & 653.99 & 0.00 & $8,605,918.51$ & 0.00 \\
\hline 344 & NWSA & 0.42 & 0.99 & 72.51 & 0.00 & 1728.27 & 0.00 & $12,074,042,902.95$ & 0.00 \\
\hline 349 & $\mathrm{OMC}$ & 0.49 & 0.99 & 12.49 & 0.00 & 0.48 & 0.99 & 111.46 & 0.00 \\
\hline 427 & $\mathrm{~T}$ & 1.46 & 0.82 & 15.70 & 0.00 & 225.71 & 0.00 & $3,282,572.27$ & 0.00 \\
\hline 438 & TMUS & 6.05 & 0.06 & 7.73 & 0.02 & 14.48 & 0.00 & $1,393,212.93$ & 0.00 \\
\hline 447 & TTWO & 2.46 & 0.55 & 25.03 & 0.00 & 426.53 & 0.00 & 387.81 & 0.00 \\
\hline 448 & TWTR & 64.62 & 0.00 & 2.65 & 0.50 & 2.96 & 0.43 & 0.02 & 1.00 \\
\hline 466 & VIAC & 2.09 & 0.65 & 3.35 & 0.35 & 15.11 & 0.00 & $311,799,076,512,593,543,168.00$ & 0.00 \\
\hline 475 & VZ & 0.65 & 0.97 & 0.91 & 0.93 & 11.90 & 0.00 & $662,223.66$ & 0.00 \\
\hline
\end{tabular}

Table A5. Long-memory nonparametric test: results for stocks belonging to the Consumer Discretionary sector.

\begin{tabular}{|c|c|c|c|c|c|c|c|c|c|}
\hline \multicolumn{2}{|c|}{ Stock } & \multicolumn{2}{|c|}{ Mean } & \multicolumn{2}{|c|}{ Variance } & \multicolumn{2}{|c|}{ Skewness } & \multicolumn{2}{|c|}{ Shape } \\
\hline ID & Ticker & Q-Stat & $p$-Value & Q-Stat & $p$-Value & Q-Stat & $p$-Value & Q-Stat & $p$-Value \\
\hline 3 & AAP & 1.69 & 0.76 & 16.81 & 0.00 & 8.40 & 0.01 & 922.06 & 0.00 \\
\hline 36 & $\mathrm{AMZN}$ & 0.63 & 0.97 & 8.17 & 0.01 & 28.05 & 0.00 & 351.68 & 0.00 \\
\hline 45 & APTV & 0.64 & 0.97 & 30.94 & 0.00 & 27.57 & 0.00 & $102,225.66$ & 0.00 \\
\hline 54 & $\mathrm{AZO}$ & 1.54 & 0.80 & 19.22 & 0.00 & 6.77 & 0.04 & $940,373.40$ & 0.00 \\
\hline 58 & BBY & 1432.42 & 0.00 & 69.71 & 0.00 & 88.99 & 0.00 & $63,814,528,225.04$ & 0.00 \\
\hline 64 & BKNG & 0.39 & 0.99 & 1.42 & 0.83 & 4.76 & 0.15 & $2,378,793,118,270.88$ & 0.00 \\
\hline 71 & BWA & 2.88 & 0.45 & 46.02 & 0.00 & 698.52 & 0.00 & $98,806.82$ & 0.00 \\
\hline 82 & CCL & 6.79 & 0.03 & 145.67 & 0.00 & 6.73 & 0.04 & 646.21 & 0.00 \\
\hline 99 & CMG & 1.10 & 0.90 & 14.41 & 0.00 & 175.62 & 0.00 & $28,421,583.74$ & 0.00 \\
\hline 121 & CZR & 152.55 & 0.00 & 2233.19 & 0.00 & 0.13 & 1.00 & $10,800.24$ & 0.00 \\
\hline 127 & DG & 9.42 & 0.00 & 495.31 & 0.00 & 18.32 & 0.00 & 103.84 & 0.00 \\
\hline 129 & $\mathrm{DHI}$ & 39.76 & 0.00 & 17.04 & 0.00 & 2.92 & 0.44 & 719.23 & 0.00 \\
\hline 136 & DLTR & 6.94 & 0.03 & 65.00 & 0.00 & 288.24 & 0.00 & $302,860,661.73$ & 0.00 \\
\hline
\end{tabular}


Table A5. Cont.

\begin{tabular}{|c|c|c|c|c|c|c|c|c|c|}
\hline \multicolumn{2}{|c|}{ Stock } & \multicolumn{2}{|c|}{ Mean } & \multicolumn{2}{|c|}{ Variance } & \multicolumn{2}{|c|}{ Skewness } & \multicolumn{2}{|l|}{ Shape } \\
\hline ID & Ticker & Q-Stat & $p$-Value & Q-Stat & $p$-Value & Q-Stat & $p$-Value & Q-Stat & $p$-Value \\
\hline 139 & $\mathrm{DPZ}$ & 6.21 & 0.05 & 16.22 & 0.00 & 8.93 & 0.01 & $34,807.52$ & 0.00 \\
\hline 141 & DRI & 0.38 & 0.99 & 69.63 & 0.00 & 0.50 & 0.99 & 75.82 & 0.00 \\
\hline 149 & EBAY & 0.29 & 1.00 & 1.91 & 0.70 & 0.01 & 1.00 & $63,267,093.69$ & 0.00 \\
\hline 165 & ETSY & 0.52 & 0.98 & 0.69 & 0.97 & 0.82 & 0.95 & 0.06 & 1.00 \\
\hline 170 & EXPE & 0.55 & 0.98 & 0.79 & 0.95 & 0.24 & 1.00 & $155,780,687,837,237,575,680.00$ & 0.00 \\
\hline 172 & $\mathrm{~F}$ & 1.20 & 0.88 & 8.49 & 0.01 & 18.99 & 0.00 & 9.25 & 0.01 \\
\hline 199 & GM & 58.12 & 0.00 & 6.02 & 0.06 & 154.47 & 0.00 & $18,879.23$ & 0.00 \\
\hline 203 & GPC & 0.48 & 0.99 & 49.54 & 0.00 & 0.09 & 1.00 & 169.79 & 0.00 \\
\hline 205 & GPS & 62.56 & 0.00 & 636.64 & 0.00 & 7.73 & 0.02 & 36.52 & 0.00 \\
\hline 206 & GRMN & 0.77 & 0.96 & 31.05 & 0.00 & 165.38 & 0.00 & $2,257,159.82$ & 0.00 \\
\hline 210 & HAS & 0.13 & 1.00 & 11.84 & 0.00 & 4.62 & 0.16 & 123.55 & 0.00 \\
\hline 212 & HBI & 0.90 & 0.94 & 7.45 & 0.02 & 191.96 & 0.00 & $275,707.95$ & 0.00 \\
\hline 214 & HD & 0.17 & 1.00 & 11.47 & 0.00 & 3.63 & 0.30 & 1632.73 & 0.00 \\
\hline 219 & HLT & 0.34 & 0.99 & 269.83 & 0.00 & 1.92 & 0.70 & 54.36 & 0.00 \\
\hline 265 & KMX & 13.41 & 0.00 & 5.07 & 0.12 & 1.57 & 0.79 & 165.34 & 0.00 \\
\hline 270 & LB & 1.17 & 0.89 & 82.90 & 0.00 & 0.69 & 0.97 & 564.99 & 0.00 \\
\hline 272 & LEG & 0.10 & 1.00 & 21.86 & 0.00 & 15.09 & 0.00 & 8.88 & 0.01 \\
\hline 273 & LEN & 0.09 & 1.00 & 36.81 & 0.00 & 11.64 & 0.00 & 6503.77 & 0.00 \\
\hline 277 & LKQ & 0.01 & 1.00 & 18.91 & 0.00 & 1.02 & 0.92 & 803.76 & 0.00 \\
\hline 282 & LOW & 1.05 & 0.91 & 9.59 & 0.00 & 4.43 & 0.18 & $24,755.76$ & 0.00 \\
\hline 286 & LVS & 4.24 & 0.21 & 2.16 & 0.63 & 192.08 & 0.00 & 384.87 & 0.00 \\
\hline 292 & MAR & 869.23 & 0.00 & 9.76 & 0.00 & 0.55 & 0.98 & 286.77 & 0.00 \\
\hline 294 & MCD & 0.47 & 0.99 & 67.09 & 0.00 & 16.64 & 0.00 & $829,057.86$ & 0.00 \\
\hline 301 & MGM & 1333.20 & 0.00 & 44.74 & 0.00 & 48.77 & 0.00 & 715.34 & 0.00 \\
\hline 302 & MHK & 1.58 & 0.79 & 152.14 & 0.00 & 0.10 & 1.00 & $4,535,476,500,387,485.00$ & 0.00 \\
\hline 323 & NCLH & 0.09 & 1.00 & 9198.76 & 0.00 & 198.22 & 0.00 & 31.27 & 0.00 \\
\hline 329 & NKE & 0.68 & 0.97 & 1.52 & 0.80 & 12.34 & 0.00 & 1.97 & 0.69 \\
\hline 341 & NVR & 0.59 & 0.98 & 60.81 & 0.00 & 0.92 & 0.93 & $93,020,233,148,373,296.00$ & 0.00 \\
\hline 342 & NWL & 2.84 & 0.46 & 13.58 & 0.00 & 1.21 & 0.88 & $2,484,344,665,315.43$ & 0.00 \\
\hline 351 & ORLY & 1.72 & 0.75 & 2.23 & 0.62 & 92.87 & 0.00 & $21,714,590.91$ & 0.00 \\
\hline 360 & PENN & 2.89 & 0.45 & 1466.13 & 0.00 & 75.61 & 0.00 & 438.73 & 0.00 \\
\hline 367 & PHM & 0.77 & 0.96 & 16.30 & 0.00 & 42.25 & 0.00 & 147.21 & 0.00 \\
\hline 375 & POOL & 2.35 & 0.58 & 1.02 & 0.92 & 3.30 & 0.36 & 579.53 & 0.00 \\
\hline 383 & $\mathrm{PVH}$ & 0.12 & 1.00 & 62.90 & 0.00 & 31.36 & 0.00 & 2239.87 & 0.00 \\
\hline 389 & RCL & 1.61 & 0.78 & 72.95 & 0.00 & 33.39 & 0.00 & 303.48 & 0.00 \\
\hline 396 & RL & 361.98 & 0.00 & 24.53 & 0.00 & 409.19 & 0.00 & $11,324.32$ & 0.00 \\
\hline 401 & ROST & 1.76 & 0.74 & 24.10 & 0.00 & 15.37 & 0.00 & 275.04 & 0.00 \\
\hline 405 & SBUX & 4.96 & 0.13 & 15.01 & 0.00 & 3.03 & 0.42 & 4.00 & 0.24 \\
\hline 435 & TGT & 2.15 & 0.64 & 3.66 & 0.29 & 12.99 & 0.00 & $502,172,473,158.29$ & 0.00 \\
\hline 436 & TJX & 1.58 & 0.79 & 12.04 & 0.00 & 0.58 & 0.98 & 739.52 & 0.00 \\
\hline 439 & TPR & 0.59 & 0.98 & 80.78 & 0.00 & 7.53 & 0.02 & $3,323,250.43$ & 0.00 \\
\hline 443 & TSCO & 0.61 & 0.98 & 411.84 & 0.00 & 46.59 & 0.00 & $555,762,781,736.86$ & 0.00 \\
\hline 444 & TSLA & 330.77 & 0.00 & 5.23 & 0.11 & 1.98 & 0.68 & 293.58 & 0.00 \\
\hline 452 & UA & 1.06 & 0.91 & 57.25 & 0.00 & 1.40 & 0.83 & 38.91 & 0.00 \\
\hline 453 & UAA & 0.16 & 1.00 & 1.43 & 0.83 & 2.26 & 0.61 & 2517.59 & 0.00 \\
\hline 457 & ULTA & 3.13 & 0.39 & 10.29 & 0.00 & 22.49 & 0.00 & $574,909,833.31$ & 0.00 \\
\hline 465 & VFC & 1.87 & 0.71 & 7.53 & 0.02 & 3.07 & 0.41 & $133,073.09$ & 0.00 \\
\hline 483 & WHR & 1.07 & 0.91 & 25.71 & 0.00 & 0.57 & 0.98 & 8124.45 & 0.00 \\
\hline 493 & WYNN & 835.20 & 0.00 & 139.23 & 0.00 & 103.23 & 0.00 & $4,842,660.01$ & 0.00 \\
\hline 499 & YUM & 1.14 & 0.89 & 66.36 & 0.00 & 1.34 & 0.85 & $1,397,654.23$ & 0.00 \\
\hline
\end{tabular}

Table A6. Long-memory nonparametric test: results for stocks belonging to the Utilities sector.

\begin{tabular}{|c|c|c|c|c|c|c|c|c|c|}
\hline \multicolumn{2}{|c|}{ Stock } & \multicolumn{2}{|c|}{ Mean } & \multicolumn{2}{|c|}{ Variance } & \multicolumn{2}{|c|}{ Skewness } & \multicolumn{2}{|c|}{ Shape } \\
\hline ID & Ticker & Q-Stat & $p$-Value & Q-Stat & $p$-Value & Q-Stat & $p$-Value & Q-Stat & $p$-Value \\
\hline 15 & AEE & 0.11 & 1.00 & 42.83 & 0.00 & 4.33 & 0.19 & 4.76 & 0.15 \\
\hline 16 & $\mathrm{AEP}$ & 0.27 & 1.00 & 59.10 & 0.00 & 172.76 & 0.00 & 2732.80 & 0.00 \\
\hline 17 & AES & 5.60 & 0.08 & 6.48 & 0.04 & 72.73 & 0.00 & 2813.28 & 0.00 \\
\hline 47 & ATO & 0.10 & 1.00 & 52.67 & 0.00 & 255.88 & 0.00 & 269.79 & 0.00 \\
\hline 52 & AWK & 0.76 & 0.96 & 41.18 & 0.00 & 0.19 & 1.00 & 8600.55 & 0.00 \\
\hline 101 & CMS & 1.29 & 0.86 & 40.46 & 0.00 & 2.43 & 0.56 & 6517.93 & 0.00 \\
\hline 103 & CNP & 0.63 & 0.97 & 8.04 & 0.01 & 0.17 & 1.00 & 0.26 & 1.00 \\
\hline 122 & $\mathrm{D}$ & 0.09 & 1.00 & 233.52 & 0.00 & 27.54 & 0.00 & $103,706.42$ & 0.00 \\
\hline 142 & DTE & 0.05 & 1.00 & 1197.20 & 0.00 & 1.96 & 0.69 & 18.78 & 0.00 \\
\hline 143 & DUK & 0.79 & 0.95 & 28.24 & 0.00 & 693.59 & 0.00 & 111.11 & 0.00 \\
\hline 151 & ED & 0.34 & 0.99 & 123.61 & 0.00 & 181.39 & 0.00 & 829.47 & 0.00 \\
\hline 153 & EIX & 0.84 & 0.95 & 9.56 & 0.00 & 11.82 & 0.00 & $205,368.73$ & 0.00 \\
\hline 161 & ES & 0.28 & 1.00 & 751.24 & 0.00 & 112.47 & 0.00 & 37.22 & 0.00 \\
\hline 164 & ETR & 0.01 & 1.00 & 38.38 & 0.00 & 209.86 & 0.00 & 136.07 & 0.00 \\
\hline 166 & EVRG & 1.70 & 0.76 & 216.15 & 0.00 & 8.98 & 0.01 & 632.36 & 0.00 \\
\hline 168 & EXC & 0.55 & 0.98 & 37.45 & 0.00 & 190.16 & 0.00 & 1693.43 & 0.00 \\
\hline 179 & $\mathrm{FE}$ & 1.63 & 0.78 & 70.87 & 0.00 & 863.97 & 0.00 & $1,500,106.76$ & 0.00 \\
\hline 281 & LNT & 0.01 & 1.00 & 27.78 & 0.00 & 71.67 & 0.00 & $10,822.32$ & 0.00 \\
\hline 325 & NEE & 0.02 & 1.00 & 104.90 & 0.00 & 0.94 & 0.93 & 2696.38 & 0.00 \\
\hline 328 & NI & 0.12 & 1.00 & 17.96 & 0.00 & 0.86 & 0.94 & 431.30 & 0.00 \\
\hline
\end{tabular}


Table A6. Cont.

\begin{tabular}{|c|c|c|c|c|c|c|c|c|c|}
\hline \multicolumn{2}{|c|}{ Stock } & \multicolumn{2}{|c|}{ Mean } & \multicolumn{2}{|c|}{ Variance } & \multicolumn{2}{|c|}{ Skewness } & \multicolumn{2}{|c|}{ Shape } \\
\hline ID & Ticker & Q-Stat & $p$-Value & Q-Stat & $p$-Value & Q-Stat & $p$-Value & Q-Stat & $p$-Value \\
\hline 335 & NRG & 189.05 & 0.00 & 304.58 & 0.00 & 444.61 & 0.00 & $1,554,966.54$ & 0.00 \\
\hline 359 & PEG & 0.76 & 0.96 & 5.62 & 0.08 & 1026.24 & 0.00 & 274.89 & 0.00 \\
\hline 374 & PNW & 0.26 & 1.00 & 61.75 & 0.00 & 18.88 & 0.00 & 107.96 & 0.00 \\
\hline 377 & PPL & 0.26 & 1.00 & 12.51 & 0.00 & 0.59 & 0.98 & 59.27 & 0.00 \\
\hline 414 & SO & 0.61 & 0.98 & 201.24 & 0.00 & 1427.79 & 0.00 & 132.94 & 0.00 \\
\hline 417 & SRE & 0.64 & 0.97 & 102.47 & 0.00 & 3.45 & 0.33 & 951.22 & 0.00 \\
\hline 480 & WEC & 0.45 & 0.99 & 23.66 & 0.00 & 458.24 & 0.00 & 158.55 & 0.00 \\
\hline 494 & XEL & 0.04 & 1.00 & 44.12 & 0.00 & 261.50 & 0.00 & 109.60 & 0.00 \\
\hline
\end{tabular}

Table A7. Long-memory nonparametric test: results for stocks belonging to the Financial sector.

\begin{tabular}{|c|c|c|c|c|c|c|c|c|c|}
\hline \multicolumn{2}{|c|}{ Stock } & \multicolumn{2}{|c|}{ Mean } & \multicolumn{2}{|c|}{ Variance } & \multicolumn{2}{|c|}{ Skewness } & \multicolumn{2}{|l|}{ Shape } \\
\hline ID & Ticker & Q-Stat & $p$-Value & Q-Stat & $p$-Value & Q-Stat & $p$-Value & Q-Stat & $p$-Value \\
\hline 18 & AFL & 0.10 & 1.00 & 7.46 & 0.02 & 0.28 & 1.00 & 413.14 & 0.00 \\
\hline 19 & AIG & 22.02 & 0.00 & 18.39 & 0.00 & 0.99 & 0.92 & 44.49 & 0.00 \\
\hline 20 & AIZ & 5.69 & 0.08 & 28.76 & 0.00 & 16.24 & 0.00 & $30,825,589.73$ & 0.00 \\
\hline 21 & AJG & 2.07 & 0.66 & 55.11 & 0.00 & 9.96 & 0.00 & 5370.54 & 0.00 \\
\hline 26 & ALL & 1.38 & 0.84 & 1.43 & 0.83 & 195.99 & 0.00 & 0.03 & 1.00 \\
\hline 34 & $\mathrm{AMP}$ & 10.21 & 0.00 & 46.94 & 0.00 & 2.29 & 0.60 & 432.26 & 0.00 \\
\hline 40 & $\mathrm{AON}$ & 0.45 & 0.99 & 1.52 & 0.80 & 0.65 & 0.97 & 401.82 & 0.00 \\
\hline 53 & $\mathrm{AXP}$ & 0.03 & 1.00 & 95.26 & 0.00 & 431.93 & 0.00 & $1,201,746,531,403,824,896.00$ & 0.00 \\
\hline 56 & BAC & 0.64 & 0.97 & 82.53 & 0.00 & 0.38 & 0.99 & 373.49 & 0.00 \\
\hline 60 & BEN & 2.00 & 0.68 & 66.81 & 0.00 & 88.36 & 0.00 & 33.25 & 0.00 \\
\hline 63 & BK & 0.27 & 1.00 & 10.47 & 0.00 & 0.08 & 1.00 & 1451.15 & 0.00 \\
\hline 66 & BLK & 2.57 & 0.53 & 8.83 & 0.01 & 4.56 & 0.17 & 15.95 & 0.00 \\
\hline 73 & $\mathrm{C}$ & 0.31 & 1.00 & 97.49 & 0.00 & 0.23 & 1.00 & 65.83 & 0.00 \\
\hline 78 & $\mathrm{CB}$ & 0.12 & 1.00 & 27.94 & 0.00 & 0.78 & 0.95 & 127.58 & 0.00 \\
\hline 79 & CBOE & 1.57 & 0.79 & 2.06 & 0.66 & 4.76 & 0.15 & 15.23 & 0.00 \\
\hline 88 & CFG & 0.26 & 1.00 & 3682.07 & 0.00 & 3.01 & 0.42 & 111.33 & 0.00 \\
\hline 93 & CINF & 4.32 & 0.19 & 177.99 & 0.00 & 72.55 & 0.00 & $138,326.80$ & 0.00 \\
\hline 96 & CMA & 0.68 & 0.97 & 255.01 & 0.00 & 10.00 & 0.00 & 88.86 & 0.00 \\
\hline 98 & CME & 0.25 & 1.00 & 6.61 & 0.04 & 2177.29 & 0.00 & 5808.24 & 0.00 \\
\hline 104 & $\mathrm{COF}$ & 1.17 & 0.89 & 351.82 & 0.00 & 18.21 & 0.00 & $387,608.07$ & 0.00 \\
\hline 126 & DFS & 0.57 & 0.98 & 106.23 & 0.00 & 14.74 & 0.00 & 2131.94 & 0.00 \\
\hline 183 & FITB & 0.72 & 0.96 & 81.80 & 0.00 & 31.18 & 0.00 & 201.83 & 0.00 \\
\hline 189 & FRC & 0.78 & 0.96 & 14.64 & 0.00 & 6.83 & 0.03 & $3,955,982.64$ & 0.00 \\
\hline 197 & GL & 1.24 & 0.87 & 434.80 & 0.00 & 349.22 & 0.00 & 1213.73 & 0.00 \\
\hline 207 & GS & 3.71 & 0.28 & 75.17 & 0.00 & 2.89 & 0.45 & 3915.39 & 0.00 \\
\hline 211 & HBAN & 0.11 & 1.00 & 23.49 & 0.00 & 8.66 & 0.01 & 1971.27 & 0.00 \\
\hline 217 & HIG & 0.28 & 1.00 & 7.32 & 0.02 & 1.59 & 0.79 & 4260.02 & 0.00 \\
\hline 231 & ICE & 1.17 & 0.89 & 0.05 & 1.00 & 20.08 & 0.00 & $10,837.07$ & 0.00 \\
\hline 249 & IVZ & 4.45 & 0.18 & 98.27 & 0.00 & 13.24 & 0.00 & $361,567,880.95$ & 0.00 \\
\hline 256 & JPM & 0.08 & 1.00 & 7.99 & 0.01 & 0.64 & 0.97 & 53.59 & 0.00 \\
\hline 258 & KEY & 0.88 & 0.94 & 193.85 & 0.00 & 1.21 & 0.88 & 2359.86 & 0.00 \\
\hline 269 & L & 2.97 & 0.43 & 141.24 & 0.00 & 4.00 & 0.24 & 80.91 & 0.00 \\
\hline 280 & LNC & 1.55 & 0.80 & 136.50 & 0.00 & 0.05 & 1.00 & 145.25 & 0.00 \\
\hline 297 & $\mathrm{MCO}$ & 2.17 & 0.63 & 24.90 & 0.00 & 5.92 & 0.07 & $627,170.28$ & 0.00 \\
\hline 300 & MET & 0.12 & 1.00 & 13.34 & 0.00 & 506.48 & 0.00 & $11,324.09$ & 0.00 \\
\hline 304 & MKTX & 288.88 & 0.00 & 3.53 & 0.32 & 32.09 & 0.00 & $26,536.35$ & 0.00 \\
\hline 306 & MMC & 0.56 & 0.98 & 0.17 & 1.00 & 0.46 & 0.99 & 6.02 & 0.06 \\
\hline 315 & MS & 30.11 & 0.00 & 72.03 & 0.00 & 0.74 & 0.96 & 110.90 & 0.00 \\
\hline 316 & MSCI & 0.26 & 1.00 & 17.33 & 0.00 & 525.90 & 0.00 & $31,422,615,411.73$ & 0.00 \\
\hline 319 & MTB & 0.08 & 1.00 & 124.24 & 0.00 & 153.78 & 0.00 & 8913.73 & 0.00 \\
\hline 324 & NDAQ & 0.42 & 0.99 & 0.35 & 0.99 & 1.04 & 0.91 & 0.80 & 0.95 \\
\hline 338 & NTRS & 1.17 & 0.89 & 31.54 & 0.00 & 0.32 & 1.00 & 30.90 & 0.00 \\
\hline 356 & РBCT & 1.55 & 0.80 & 238.25 & 0.00 & 2558.81 & 0.00 & 6255.71 & 0.00 \\
\hline 363 & PFG & 3.47 & 0.33 & 25.39 & 0.00 & 126.03 & 0.00 & $12,093.15$ & 0.00 \\
\hline 365 & PGR & 0.76 & 0.96 & 19.71 & 0.00 & 323.52 & 0.00 & $64,294.76$ & 0.00 \\
\hline 372 & PNC & 0.14 & 1.00 & 137.22 & 0.00 & 1.95 & 0.69 & 1199.57 & 0.00 \\
\hline 379 & PRU & 0.30 & 1.00 & 99.70 & 0.00 & 16.01 & 0.00 & $20,748,890,009.28$ & 0.00 \\
\hline 390 & RE & 1.74 & 0.75 & 12.29 & 0.00 & 572.82 & 0.00 & 0.01 & 1.00 \\
\hline 393 & RF & 0.60 & 0.98 & 25.74 & 0.00 & 6.47 & 0.04 & 680.50 & 0.00 \\
\hline 395 & RJF & 0.42 & 0.99 & 24.43 & 0.00 & 0.03 & 1.00 & 53.72 & 0.00 \\
\hline 406 & SCHW & 2.14 & 0.64 & 34.52 & 0.00 & 0.02 & 1.00 & 532.19 & 0.00 \\
\hline 409 & SIVB & 0.56 & 0.98 & 82.25 & 0.00 & 1.27 & 0.86 & $19,650.78$ & 0.00 \\
\hline 416 & SPGI & 6.13 & 0.06 & 8.24 & 0.01 & 5.46 & 0.09 & 905.36 & 0.00 \\
\hline 419 & STT & 2.33 & 0.59 & 50.81 & 0.00 & 7.83 & 0.02 & 658.05 & 0.00 \\
\hline 424 & SYF & 10.09 & 0.00 & 2632.83 & 0.00 & 10.76 & 0.00 & 1337.48 & 0.00 \\
\hline 433 & TFC & 0.20 & 1.00 & 163.44 & 0.00 & 2.49 & 0.55 & 0.40 & 0.99 \\
\hline 441 & TROW & 1013.25 & 0.00 & 14.75 & 0.00 & 2.31 & 0.59 & 407.78 & 0.00 \\
\hline 442 & TRV & 0.93 & 0.93 & 107.18 & 0.00 & 0.38 & 0.99 & 4663.98 & 0.00 \\
\hline 459 & UNM & 1.76 & 0.74 & 242.95 & 0.00 & 6.06 & 0.06 & $10,564.73$ & 0.00 \\
\hline 463 & USB & 0.05 & 1.00 & 87.10 & 0.00 & 202.19 & 0.00 & 477.28 & 0.00 \\
\hline 482 & WFC & 0.01 & 1.00 & 25.70 & 0.00 & 5.14 & 0.11 & 574.50 & 0.00 \\
\hline 484 & WLTW & 1.75 & 0.74 & 7.41 & 0.02 & 12.33 & 0.00 & 210.72 & 0.00 \\
\hline 488 & WRB & 0.06 & 1.00 & 58.69 & 0.00 & 70.09 & 0.00 & 354.54 & 0.00 \\
\hline 502 & ZION & 1.71 & 0.75 & 9.46 & 0.00 & 17.12 & 0.00 & 1213.46 & 0.00 \\
\hline
\end{tabular}


Table A8. Long-memory nonparametric test: results for stocks belonging to the Materials sector.

\begin{tabular}{|c|c|c|c|c|c|c|c|c|c|}
\hline \multicolumn{2}{|c|}{ Stock } & \multicolumn{2}{|c|}{ Mean } & \multicolumn{2}{|c|}{ Variance } & \multicolumn{2}{|c|}{ Skewness } & \multicolumn{2}{|c|}{ Shape } \\
\hline ID & Ticker & Q-Stat & $p$-Value & Q-Stat & $p$-Value & Q-Stat & $p$-Value & Q-Stat & $p$-Value \\
\hline 23 & ALB & 1.04 & 0.91 & 23.58 & 0.00 & 42.90 & 0.00 & 50.53 & 0.00 \\
\hline 30 & AMCR & 19.24 & 0.00 & 158749.17 & 0.00 & 0.31 & 1.00 & 15.43 & 0.00 \\
\hline 43 & APD & 0.83 & 0.95 & 4.47 & 0.18 & 1.04 & 0.91 & 387.64 & 0.00 \\
\hline 51 & AVY & 0.21 & 1.00 & 10.23 & 0.00 & 0.06 & 1.00 & $2,282,202,533.61$ & 0.00 \\
\hline 67 & BLL & 0.41 & 0.99 & 48.50 & 0.00 & 203.70 & 0.00 & 134.49 & 0.00 \\
\hline 85 & $\mathrm{CE}$ & 0.29 & 1.00 & 6.00 & 0.06 & 137.50 & 0.00 & $155,026.65$ & 0.00 \\
\hline 87 & $\mathrm{CF}$ & 2.21 & 0.62 & 19.38 & 0.00 & 3.54 & 0.31 & 4724.43 & 0.00 \\
\hline 117 & CTVA & 0.82 & 0.95 & 6.71 & 0.04 & 1135.99 & 0.00 & 1571.97 & 0.00 \\
\hline 124 & DD & 0.72 & 0.96 & 21.97 & 0.00 & 12.71 & 0.00 & $171,927.86$ & 0.00 \\
\hline 138 & DOW & 2.86 & 0.46 & 105.60 & 0.00 & 5.36 & 0.10 & 172.94 & 0.00 \\
\hline 150 & ECL & 0.03 & 1.00 & 3.01 & 0.42 & 0.17 & 1.00 & 207.26 & 0.00 \\
\hline 155 & EMN & 1.41 & 0.83 & 74.64 & 0.00 & 26.98 & 0.00 & $32,498.79$ & 0.00 \\
\hline 177 & FCX & 468.69 & 0.00 & 156.78 & 0.00 & 18.30 & 0.00 & 7587.42 & 0.00 \\
\hline 186 & FMC & 1.07 & 0.91 & 27.93 & 0.00 & 1.97 & 0.69 & $70,699.93$ & 0.00 \\
\hline 234 & IFF & 0.98 & 0.92 & 15.37 & 0.00 & 0.47 & 0.99 & $30,824.92$ & 0.00 \\
\hline 240 & IP & 3.55 & 0.31 & 9.18 & 0.01 & 1.22 & 0.87 & 4870.79 & 0.00 \\
\hline 276 & LIN & 1.70 & 0.76 & 23.52 & 0.00 & 2.88 & 0.45 & $21,444.77$ & 0.00 \\
\hline 288 & LYB & 840.24 & 0.00 & 5.41 & 0.09 & 4.96 & 0.13 & 3011.29 & 0.00 \\
\hline 305 & MLM & 1.51 & 0.81 & 2.81 & 0.47 & 0.10 & 1.00 & $132,421,508.70$ & 0.00 \\
\hline 310 & MOS & 0.55 & 0.98 & 105.00 & 0.00 & 0.19 & 1.00 & 2623.76 & 0.00 \\
\hline 326 & NEM & 72.63 & 0.00 & 5.28 & 0.10 & 0.15 & 1.00 & 33.99 & 0.00 \\
\hline 339 & NUE & 0.48 & 0.99 & 840.43 & 0.00 & 3.52 & 0.32 & $401,742,062.49$ & 0.00 \\
\hline 368 & PKG & 2.40 & 0.57 & 3.50 & 0.32 & 77.31 & 0.00 & $19,504.28$ & 0.00 \\
\hline 376 & PPG & 0.10 & 1.00 & 23.30 & 0.00 & 0.14 & 1.00 & 1555.03 & 0.00 \\
\hline 407 & SEE & 0.16 & 1.00 & 58.50 & 0.00 & 0.50 & 0.99 & $12,707.18$ & 0.00 \\
\hline 408 & SHW & 0.00 & 1.00 & 197.59 & 0.00 & 3.47 & 0.33 & $689,594.11$ & 0.00 \\
\hline 468 & VMC & 6.11 & 0.06 & 2.14 & 0.64 & 4.94 & 0.13 & 191.93 & 0.00 \\
\hline 489 & WRK & 1.74 & 0.75 & 164.38 & 0.00 & 9.28 & 0.00 & 13.10 & 0.00 \\
\hline
\end{tabular}

Table A9. Long-memory nonparametric test: results for stocks belonging to the Real Estate sector.

\begin{tabular}{|c|c|c|c|c|c|c|c|c|c|}
\hline \multicolumn{2}{|c|}{ Stock } & \multicolumn{2}{|c|}{ Mean } & \multicolumn{2}{|c|}{ Variance } & \multicolumn{2}{|c|}{ Skewness } & \multicolumn{2}{|c|}{ Shape } \\
\hline ID & Ticker & Q-Stat & $p$-Value & Q-Stat & $p$-Value & Q-Stat & $p$-Value & Q-Stat & $p$-Value \\
\hline 35 & AMT & 0.58 & 0.98 & 2.90 & 0.45 & 1.86 & 0.71 & 0.07 & 1.00 \\
\hline 46 & ARE & 0.07 & 1.00 & 1.92 & 0.70 & 86.33 & 0.00 & 362.03 & 0.00 \\
\hline 49 & AVB & 1.60 & 0.78 & 13.19 & 0.00 & 1392.96 & 0.00 & 1852.41 & 0.00 \\
\hline 72 & $\mathrm{BXP}$ & 0.05 & 1.00 & 195.25 & 0.00 & 0.01 & 1.00 & 687.96 & 0.00 \\
\hline 80 & CBRE & 1.04 & 0.91 & 11.00 & 0.00 & 56.40 & 0.00 & $1,075,058,567.14$ & 0.00 \\
\hline 81 & CCI & 1.89 & 0.71 & 11.40 & 0.00 & 18.79 & 0.00 & 4765.86 & 0.00 \\
\hline 135 & DLR & 0.40 & 0.99 & 184.57 & 0.00 & 111.93 & 0.00 & $1,996,169.04$ & 0.00 \\
\hline 140 & DRE & 1.92 & 0.70 & 1.37 & 0.84 & 5.07 & 0.12 & 114.05 & 0.00 \\
\hline 159 & EQIX & 0.50 & 0.99 & 15.59 & 0.00 & 0.33 & 1.00 & 513.91 & 0.00 \\
\hline 160 & EQR & 0.45 & 0.99 & 13.34 & 0.00 & 2135.07 & 0.00 & 2673.21 & 0.00 \\
\hline 162 & ESS & 0.29 & 1.00 & 10.45 & 0.00 & 11.08 & 0.00 & 1.28 & 0.86 \\
\hline 171 & EXR & 0.28 & 1.00 & 2.73 & 0.49 & 1.01 & 0.92 & 249.22 & 0.00 \\
\hline 190 & FRT & 0.25 & 1.00 & 90.68 & 0.00 & 0.79 & 0.95 & 185.83 & 0.00 \\
\hline 226 & HST & 1.29 & 0.86 & 9.56 & 0.00 & 185.19 & 0.00 & 1618.23 & 0.00 \\
\hline 245 & IRM & 2.71 & 0.49 & 3.78 & 0.27 & 402.35 & 0.00 & $153,389.74$ & 0.00 \\
\hline 261 & KIM & 101.66 & 0.00 & 72.41 & 0.00 & 7.60 & 0.02 & 366.48 & 0.00 \\
\hline 291 & MAA & 0.06 & 1.00 & 24.87 & 0.00 & 121.52 & 0.00 & 331.69 & 0.00 \\
\hline 346 & $\mathrm{O}$ & 0.78 & 0.95 & 725.34 & 0.00 & 14.55 & 0.00 & 37.77 & 0.00 \\
\hline 358 & PEAK & 0.90 & 0.94 & 137.87 & 0.00 & 183.60 & 0.00 & 100.41 & 0.00 \\
\hline 370 & PLD & 1.84 & 0.72 & 2.82 & 0.46 & 46.41 & 0.00 & 707.18 & 0.00 \\
\hline 380 & PSA & 0.26 & 1.00 & 44.84 & 0.00 & 13.88 & 0.00 & 2020.36 & 0.00 \\
\hline 391 & REG & 0.16 & 1.00 & 84.56 & 0.00 & 1.42 & 0.83 & 4.42 & 0.18 \\
\hline 404 & SBAC & 0.14 & 1.00 & 20.17 & 0.00 & 41.75 & 0.00 & 0.03 & 1.00 \\
\hline 415 & SPG & 0.41 & 0.99 & 464.66 & 0.00 & 25.80 & 0.00 & 53.20 & 0.00 \\
\hline 455 & UDR & 0.39 & 0.99 & 52.33 & 0.00 & 62.97 & 0.00 & 2895.68 & 0.00 \\
\hline 469 & VNO & 0.25 & 1.00 & 74.77 & 0.00 & 0.58 & 0.98 & 431.73 & 0.00 \\
\hline 473 & VTR & 2.42 & 0.56 & 117.14 & 0.00 & 67.70 & 0.00 & $1,462,488.27$ & 0.00 \\
\hline 481 & WELL & 0.20 & 1.00 & 258.05 & 0.00 & 121.19 & 0.00 & 7311.74 & 0.00 \\
\hline 492 & WY & 9.29 & 0.00 & 134.50 & 0.00 & 15.74 & 0.00 & 38.15 & 0.00 \\
\hline
\end{tabular}


Table A10. Long-memory nonparametric test: results for stocks belonging to the Consumer Staples sector.

\begin{tabular}{|c|c|c|c|c|c|c|c|c|c|}
\hline \multicolumn{2}{|c|}{ Stock } & \multicolumn{2}{|c|}{ Mean } & \multicolumn{2}{|c|}{ Variance } & \multicolumn{2}{|c|}{ Skewness } & \multicolumn{2}{|l|}{ Shape } \\
\hline ID & Ticker & Q-Stat & $p$-Value & Q-Stat & $p$-Value & Q-Stat & $p$-Value & Q-Stat & $p$-Value \\
\hline 12 & $\mathrm{ADM}$ & 1.66 & 0.77 & 11.45 & 0.00 & 16.89 & 0.00 & 15.16 & 0.00 \\
\hline 74 & CAG & 0.17 & 1.00 & 35.57 & 0.00 & 196.12 & 0.00 & $552,087.57$ & 0.00 \\
\hline 89 & $\mathrm{CHD}$ & 3.46 & 0.33 & 5.78 & 0.07 & 13.87 & 0.00 & 30.36 & 0.00 \\
\hline 94 & CL & 1.13 & 0.89 & 115.07 & 0.00 & 2.29 & 0.60 & 41.63 & 0.00 \\
\hline 95 & CLX & 1.47 & 0.82 & 1.21 & 0.88 & 48.10 & 0.00 & 1.11 & 0.90 \\
\hline 108 & COST & 1.34 & 0.85 & 0.93 & 0.93 & 155.15 & 0.00 & 923.19 & 0.00 \\
\hline 109 & СРB & 2.46 & 0.55 & 18.84 & 0.00 & 13.10 & 0.00 & $14,191,017.32$ & 0.00 \\
\hline 154 & EL & 0.21 & 1.00 & 9.28 & 0.00 & 0.18 & 1.00 & 12.26 & 0.00 \\
\hline 196 & GIS & 1.98 & 0.68 & 2.16 & 0.63 & 0.75 & 0.96 & $869,261,422,467.77$ & 0.00 \\
\hline 224 & HRL & 0.62 & 0.98 & 2.97 & 0.43 & 41.36 & 0.00 & $266,212.51$ & 0.00 \\
\hline 227 & HSY & 3.20 & 0.38 & 1.58 & 0.79 & 4.39 & 0.19 & $13,408.11$ & 0.00 \\
\hline 257 & $\mathrm{~K}$ & 1.33 & 0.85 & 19.70 & 0.00 & 4.06 & 0.23 & $20,494,513.99$ & 0.00 \\
\hline 260 & KHC & 0.13 & 1.00 & 38.44 & 0.00 & 2.23 & 0.61 & 7734.06 & 0.00 \\
\hline 263 & KMB & 1.86 & 0.71 & 22.93 & 0.00 & 11.99 & 0.00 & 87.97 & 0.00 \\
\hline 266 & $\mathrm{KO}$ & 0.13 & 1.00 & 41.31 & 0.00 & 102.34 & 0.00 & 8656.05 & 0.00 \\
\hline 267 & $\mathrm{KR}$ & 1.81 & 0.73 & 0.09 & 1.00 & 185.45 & 0.00 & $206,368.10$ & 0.00 \\
\hline 287 & LW & 0.27 & 1.00 & 844.20 & 0.00 & 316.08 & 0.00 & 1898.22 & 0.00 \\
\hline 298 & MDLZ & 0.99 & 0.92 & 270.91 & 0.00 & 2.80 & 0.47 & 232.49 & 0.00 \\
\hline 303 & MKC & 3.39 & 0.34 & 15.03 & 0.00 & 10.65 & 0.00 & $78,669,023,663,671,856.00$ & 0.00 \\
\hline 308 & MNST & 212.71 & 0.00 & 7.37 & 0.02 & 1.27 & 0.86 & 415.85 & 0.00 \\
\hline 309 & $\mathrm{MO}$ & 6.86 & 0.03 & 16.16 & 0.00 & 99.86 & 0.00 & 63.68 & 0.00 \\
\hline 361 & PEP & 0.10 & 1.00 & 7.88 & 0.02 & 5.49 & 0.09 & 1127.60 & 0.00 \\
\hline 364 & PG & 4.83 & 0.14 & 55.27 & 0.00 & 163.60 & 0.00 & 65.11 & 0.00 \\
\hline 371 & PM & 0.30 & 1.00 & 15.44 & 0.00 & 1.69 & 0.76 & $154,030,094,291.82$ & 0.00 \\
\hline 410 & SJM & 57.29 & 0.00 & 0.78 & 0.95 & 509.02 & 0.00 & 7280.62 & 0.00 \\
\hline 421 & STZ & 1.46 & 0.82 & 57.67 & 0.00 & 36.10 & 0.00 & $10,475,104.79$ & 0.00 \\
\hline 426 & SYY & 0.01 & 1.00 & 291.70 & 0.00 & 0.27 & 1.00 & 18.41 & 0.00 \\
\hline 428 & TAP & 0.97 & 0.92 & 33.64 & 0.00 & 54.26 & 0.00 & $264,885,029,611.89$ & 0.00 \\
\hline 445 & TSN & 333.93 & 0.00 & 8.46 & 0.01 & 1100.99 & 0.00 & $24,018.10$ & 0.00 \\
\hline 478 & WBA & 0.11 & 1.00 & 0.05 & 1.00 & 22.78 & 0.00 & 171.48 & 0.00 \\
\hline 487 & WMT & 0.23 & 1.00 & 1.78 & 0.74 & 5.42 & 0.09 & 4337.34 & 0.00 \\
\hline
\end{tabular}

Table A11. Long-memory nonparametric test: results for stocks belonging to the Energy sector.

\begin{tabular}{|c|c|c|c|c|c|c|c|c|c|}
\hline \multicolumn{2}{|c|}{ Stock } & \multicolumn{2}{|c|}{ Mean } & \multicolumn{2}{|c|}{ Variance } & \multicolumn{2}{|c|}{ Skewness } & \multicolumn{2}{|c|}{ Shape } \\
\hline ID & Ticker & Q-Stat & $p$-Value & Q-Stat & $p$-Value & Q-Stat & $p$-Value & Q-Stat & $p$-Value \\
\hline 42 & APA & 18.44 & 0.00 & 108.43 & 0.00 & 25.19 & 0.00 & 1041.36 & 0.00 \\
\hline 65 & BKR & 0.24 & 1.00 & 4.57 & 0.17 & 0.21 & 1.00 & 2113.11 & 0.00 \\
\hline 105 & $\mathrm{COG}$ & 0.78 & 0.96 & 5.24 & 0.11 & 540.21 & 0.00 & 0.17 & 1.00 \\
\hline 107 & $\mathrm{COP}$ & 127.06 & 0.00 & 69.03 & 0.00 & 249.34 & 0.00 & 485.46 & 0.00 \\
\hline 120 & CVX & 0.08 & 1.00 & 11.10 & 0.00 & 11.40 & 0.00 & $408,723.10$ & 0.00 \\
\hline 145 & DVN & 73.89 & 0.00 & 179.59 & 0.00 & 4.45 & 0.18 & 341.66 & 0.00 \\
\hline 158 & EOG & 0.14 & 1.00 & 13.09 & 0.00 & 1763.58 & 0.00 & 737.63 & 0.00 \\
\hline 173 & FANG & 0.10 & 1.00 & 876.44 & 0.00 & 30.68 & 0.00 & 103.99 & 0.00 \\
\hline 209 & HAL & 5.12 & 0.11 & 38.16 & 0.00 & 4.06 & 0.23 & 76.40 & 0.00 \\
\hline 215 & HES & 68.38 & 0.00 & 44.80 & 0.00 & 17.57 & 0.00 & 154.14 & 0.00 \\
\hline 216 & $\mathrm{HFC}$ & 434.33 & 0.00 & 6.87 & 0.03 & 28.83 & 0.00 & 482.16 & 0.00 \\
\hline 264 & KMI & 0.69 & 0.97 & 343.00 & 0.00 & 27.28 & 0.00 & 582.49 & 0.00 \\
\hline 311 & MPC & 1.29 & 0.86 & 4.13 & 0.22 & 522.03 & 0.00 & 8650.36 & 0.00 \\
\hline 314 & MRO & 92.63 & 0.00 & 265.39 & 0.00 & 30.26 & 0.00 & 40.33 & 0.00 \\
\hline 333 & NOV & 121.13 & 0.00 & 72.49 & 0.00 & 8.35 & 0.01 & $99,678.31$ & 0.00 \\
\hline 348 & OKE & 3.96 & 0.24 & 612.81 & 0.00 & 997.01 & 0.00 & 606.72 & 0.00 \\
\hline 353 & OXY & 4.15 & 0.22 & 134.08 & 0.00 & 566.34 & 0.00 & $184,685.22$ & 0.00 \\
\hline 381 & PSX & 16.35 & 0.00 & 9.51 & 0.00 & 5.50 & 0.09 & $11,185,126.83$ & 0.00 \\
\hline 385 & PXD & 1.32 & 0.85 & 6.69 & 0.04 & 7.56 & 0.02 & 590.97 & 0.00 \\
\hline 411 & SLB & 3.93 & 0.25 & 22.63 & 0.00 & 37.13 & 0.00 & 3167.17 & 0.00 \\
\hline 467 & VLO & 3.17 & 0.39 & 17.30 & 0.00 & 79.05 & 0.00 & $925,056,523.49$ & 0.00 \\
\hline 486 & WMB & 0.23 & 1.00 & 242.48 & 0.00 & 0.41 & 0.99 & 873.35 & 0.00 \\
\hline 496 & $\mathrm{XOM}$ & 0.01 & 1.00 & 7.76 & 0.02 & 2.09 & 0.65 & 77.50 & 0.00 \\
\hline
\end{tabular}

\section{References}

1. Hurst, H.E. Long-term storage capacity of reservoirs. Trans. Am. Soc. Civ. Eng. 1951, 116, 770-799. [CrossRef]

2. Mandelbrot, B.B.; Van Ness, J.W. Fractional Brownian motions, fractional noises and applications. SIAM Rev. 1968, $10,422-437$. [CrossRef]

3. Granger, C.W. The typical spectral shape of an economic variable. Econom. J. Econom. Soc. 1966, 34, 150-161. [CrossRef]

4. Greene, M.T.; Fielitz, B.D. Long-term dependence in common stock returns. J. Financ. Econ. 1977, 4, 339-349. [CrossRef]

5. Lo, A.W. Long-term memory in stock market prices. Econom. J. Econom. Soc. 1991, 59, 1279-1313. [CrossRef]

6. Mattera, R.; Sciorio, F.D. Option Pricing Under Multifractional Process and Long-Range Dependence. Fluct. Noise Lett. 2021, 20, 2150008. [CrossRef] 
7. Ding, Z.; Granger, C.; Engle, R. A long memory property of stock market returns and a new model. J. Empir. Financ. 1993, 1, 83-106. [CrossRef]

8. Ding, Z.; Granger, C. Modeling volatility persistence of speculative returns: A new approach. J. Econom. 1996, 73, 185-215 [CrossRef]

9. Crato, N.; de Lima, P. Long-range dependence in the conditional variance of stock returns. Econ. Lett. 1994, 45, 281-285. [CrossRef]

10. Lo, A.W.; MacKinlay, A.C. Stock market prices do not follow random walks: Evidence from a simple specification test. Rev. Financ. Stud. 1988, 1, 41-66. [CrossRef]

11. Lo, A.W.; MacKinlay, A.C. When are contrarian profits due to stock market overreaction? Rev. Financ. Stud. 1990, 3, 175-205. [CrossRef]

12. Mills, T. Is there long-term memory in UK stock returns? Appl. Financ. Econ. 1993, 3, 303-306. [CrossRef]

13. Cheung, Y.W.; Lai, K. A search for long memory in international stock market returns. J. Int. Money Financ. 1995, 14, 597-615. [CrossRef]

14. Resende, M.; Teixeira, N. Permanent structural changes in the Brazilian economy and long memory: A stock market perspective. Appl. Econ. Lett. 2002, 9, 373-375. [CrossRef]

15. Jefferis, K.; Thupayagale, P. Long memory in Southern African stock markets. S. Afr. J. Econ. 2008, 76, 384-398. [CrossRef]

16. Bhattacharya, S.N.; Bhattacharya, M.; Guhathakurta, K. The Comparative Dynamics of Developed and Emerging Stock Markets: A Long Memory Perspective. Theor. Econ. Lett. 2018, 8, 1493-1509. [CrossRef]

17. Lillo, F.; Farmer, J.D. The long memory of the efficient market. Stud. Nonlinear Dyn. Econom. 2004, 8, 1. [CrossRef]

18. Kang, S.H.; Yoon, S.M. Long memory properties in return and volatility: Evidence from the Korean stock market. Phys. A Stat. Mech. Its Appl. 2007, 385, 591-600. [CrossRef]

19. Arouri, M.E.H.; Hammoudeh, S.; Lahiani, A.; Nguyen, D.K. Long memory and structural breaks in modeling the return and volatility dynamics of precious metals. Q. Rev. Econ. Financ. 2012, 52, 207-218. [CrossRef]

20. Al-Yahyaee, K.H.; Mensi, W.; Yoon, S.M. Efficiency, multifractality, and the long-memory property of the Bitcoin market: A comparative analysis with stock, currency, and gold markets. Financ. Res. Lett. 2018, 27, 228-234. [CrossRef]

21. Ray, B.; Tsay, R. Long-range dependence in daily stock volatilities. J. Bus. Econ. Stat. 2000, 18, 254-262. [CrossRef]

22. Christensen, B.; Nielsen, M. The effect of long memory in volatility on stock market fluctuations. Rev. Econ. Stat. 2007, 89, 684-700. doi: 10.1162/rest.89.4.684. [CrossRef]

23. Granero, M.S.; Segovia, J.T.; Pérez, J.G. Some comments on Hurst exponent and the long memory processes on capital markets. Phys. A Stat. Mech. Its Appl. 2008, 387, 5543-5551. [CrossRef]

24. Perron, P.; Qu, Z. Long-memory and level shifts in the volatility of stock market return indices. J. Bus. Econ. Stat. 2010, 28, 275-290. [CrossRef]

25. Nguyen, D.B.B.; Prokopczuk, M.; Sibbertsen, P. The memory of stock return volatility: Asset pricing implications. J. Financ. Mark. 2020, 47, 100487. [CrossRef]

26. Lobato, I.; Savin, N. Real and spurious long-memory properties of stock-market data. J. Bus. Econ. Stat. 1998, 16, 261-268. [CrossRef]

27. Granger, C.; Hyung, N. Occasional structural breaks and long memory with an application to the S\&P 500 absolute stock returns J. Empir. Financ. 2004, 11, 399-421. [CrossRef]

28. Chatzikonstanti, V.; Venetis, I. Long memory in log-range series: Do structural breaks matter? J. Empir. Financ. 2015, 33, 104-113. [CrossRef]

29. Patton, A.J. On the out-of-sample importance of skewness and asymmetric dependence for asset allocation. J. Financ. Econom. 2004, 2, 130-168. [CrossRef]

30. Jondeau, E.; Rockinger, M. Optimal portfolio allocation under higher moments. Eur. Financ. Manag. 2006, 12, 29-55. [CrossRef]

31. Harvey, C.R.; Liechty, J.C.; Liechty, M.W.; Müller, P. Portfolio selection with higher moments. Quant. Financ. 2010, 10, 469-485. [CrossRef]

32. Jondeau, E.; Rockinger, M. On the importance of time variability in higher moments for asset allocation. J. Financ. Econom. 2012, 10, 84-123. [CrossRef]

33. Mattera, R.; Giacalone, M.; Gibert, K. Distribution-Based Entropy Weighting Clustering of Skewed and Heavy Tailed Time Series Symmetry 2021, 13, 959. [CrossRef]

34. Harvey, C.R.; Siddique, A. Conditional skewness in asset pricing tests. J. Financ. 2000, 55, 1263-1295. [CrossRef]

35. Scott, R.C.; Horvath, P.A. On the direction of preference for moments of higher order than the variance. J. Financ. 1980, 35, 915-919. [CrossRef]

36. Harvey, C.R.; Siddique, A. Autoregressive conditional skewness. J. Financ. Quant. Anal. 1999, 34, 465-487. [CrossRef]

37. Jondeau, E.; Rockinger, M. Conditional volatility, skewness, and kurtosis: Existence, persistence, and comovements. J. Econ. Dyn. Control 2003, 27, 1699-1737. [CrossRef]

38. León, Á.; Rubio, G.; Serna, G. Autoregresive conditional volatility, skewness and kurtosis. Q. Rev. Econ. Financ. 2005, 45, 599-618. [CrossRef]

39. Cerqueti, R.; Giacalone, M.; Mattera, R. Model-based fuzzy time series clustering of conditional higher moments. Int. J. Approx. Reason. 2021, 134, 34-52. [CrossRef] 
40. Gromykov, G.; Haye, M.O.; Philippe, A. A Frequency-domain test for long range dependence. Stat. Inference Stoch. Process. 2018, 21, 513-526. [CrossRef]

41. Creal, D.; Koopman, S.J.; Lucas, A. Generalized autoregressive score models with applications. J. Appl. Econom. 2013, 28, 777-795. [CrossRef]

42. Adcock, C.; Eling, M.; Loperfido, N. Skewed distributions in finance and actuarial science: A review. Eur. J. Financ. 2015, 21, 1253-1281. [CrossRef]

43. Cerqueti, R.; Giacalone, M.; Mattera, R. Skewed non-Gaussian GARCH models for cryptocurrencies volatility modelling. Inf. Sci. 2020, 527, 1-26. [CrossRef]

44. Cont, R. Empirical properties of asset returns: Stylized facts and statistical issues. Quant. Financ. 2001, 1, 223. [CrossRef]

45. Mattera, R.; Giacalone, M. Alternative distribution based GARCH models for bitcoin volatility estimation. Empir. Econ. Lett. 2018, 17, 1283-1288.

46. Zhu, D.; Galbraith, J.W. A generalized asymmetric Student-t distribution with application to financial econometrics. J. Econom. 2010, 157, 297-305. [CrossRef]

47. Theodossiou, P. Financial data and the skewed generalized t distribution. Manag. Sci. 1998, 44, 1650-1661. [CrossRef]

48. Giacalone, M.; Panarello, D.; Mattera, R. Multicollinearity in regression: An efficiency comparison between L p-norm and least squares estimators. Qual. Quant. 2018, 52, 1831-1859. [CrossRef]

49. Mattera, R.; Giacalone, M. Forecasting macroeconomic volatility with score-driven models. Stat. Appl. 2020, 18, 177-196.

50. Fernández, C.; Steel, M.F. On Bayesian modeling of fat tails and skewness. J. Am. Stat. Assoc. 1998, 93, 359-371.

51. Cerqueti, R.; Giacalone, M.; Panarello, D. A Generalized Error Distribution Copula-based method for portfolios risk assessment. Phys. A Stat. Mech. Its Appl. 2019, 524, 687-695. [CrossRef] 